\title{
Onecut1 Is Essential for Horizontal Cell Genesis and Retinal Integrity
}

\author{
Fuguo Wu, ${ }^{1,2,3}$ Renzhong Li, ${ }^{1,2,3}$ Yumiko Umino, ${ }^{3,5}$ Tadeusz J. Kaczynski, ${ }^{1,2,3}$ Darshan Sapkota, ${ }^{1,2,3}$ Shengguo Li, ${ }^{6}$ \\ Mengqing Xiang, ${ }^{6}$ Steven J. Fliesler, ${ }^{1,3,7}$ David M. Sherry, ${ }^{8}$ Maureen Gannon, ${ }^{9}$ Eduardo Solessio, ${ }^{3,5}$ and Xiuqian Mu ${ }^{1,2,3,4}$ \\ ${ }^{1}$ Department of Ophthalmology/Ross Eye Institute and ${ }^{2}$ Developmental Genomics Group, New York State Center of Excellence in Bioinformatics and Life \\ Sciences, University at Buffalo, Buffalo, New York 14203, ${ }^{3}$ SUNY Eye Institute, Buffalo, New York 14203, ${ }^{4}$ CCSG Genetics Program, Roswell Park Cancer \\ Institute, Buffalo, New York 14263, ${ }^{5}$ Department of Ophthalmology, Upstate Medical University, Syracuse, New York 13210, ${ }^{6}$ Center for Advanced \\ Biotechnology and Medicine, University of Medicine and Dentistry of New Jersey-Robert Wood Johnson Medical School, Piscataway, New Jersey 08854, \\ ${ }^{7}$ Research Service, Veterans Administration Western New York Healthcare System, Buffalo, New York 14215, ${ }^{8}$ Department of Cell Biology, Oklahoma \\ Center for Neurosciences and Department of Pharmaceutical Sciences, University of Oklahoma Health Sciences Center, Oklahoma City, Oklahoma 73126, \\ and ${ }^{~}$ Department of Medicine, Vanderbilt University Medical Center, Nashville, Tennessee 37232
}

Horizontal cells are interneurons that synapse with photoreceptors in the outer retina. Their genesis during development is subject to regulation by transcription factors in a hierarchical manner. Previously, we showed that Onecut $1(0 \mathrm{cl})$, an atypical homeodomain transcription factor, is expressed in developing horizontal cells (HCs) and retinal ganglion cells (RGCs) in the mouse retina. Herein, by knocking out $O c 1$ specifically in the developing retina, we show that the majority $(\sim 80 \%)$ of HCs fail to form during early retinal development, implying that $\mathrm{Ocl}$ is essential for $\mathrm{HC}$ genesis. However, no other retinal cell types, including RGCs, were affected in the $O c 1$ knock-out. Analysis of the genetic relationship between $O c 1$ and other transcription factor genes required for $\mathrm{HC}$ development revealed that Oc1 functions downstream of FoxN4, in parallel with Ptf1a, but upstream of Lim1 and Prox1. By in utero electroporation, we found that $\mathrm{Ocl}$ and Ptfla together are not only essential, but also sufficient for determination of $\mathrm{HC}$ fate. In addition, the synaptic connections in the outer plexiform layer are defective in $0 c 1$-null mice, and photoreceptors undergo age-dependent degeneration, indicating that HCs are not only an integral part of the retinal circuitry, but also are essential for the survival of photoreceptors. In sum, these results demonstrate that $\mathrm{Ocl}$ is a critical determinant of $\mathrm{HC}$ fate, and reveal that $\mathrm{HCs}$ are essential for photoreceptor viability, retinal integrity, and normal visual function.

\section{Introduction}

In the vertebrate retina, there are six types of neurons (rod and cone photoreceptors, horizontal cells (HCs), bipolar cells, amacrine cells, and retinal ganglion cells (RGCs)), and one glial cell type (Müller cells). Each of these cell types plays a distinct role in the process of vision (Wässle and Boycott, 1991; Masland, 2001).

Received Jan. 9, 2013; revised June 24, 2013; accepted July 1, 2013.

Author contributions: E.S. and X.M. designed research; F.W., R.L., Y.U., T.J.K., D.S., S.L., M.X., S.J.F., D.M.S., and M.G. performed research; F.W., Y.U., D.M.S., E.S., and X.M. analyzed data; X.M. wrote the paper.

This project was supported by grants from the Whitehall Foundation (X.M.); the National Eye Institute (EY020545, X.M.; EY007361, S.J.F.; EY012190 to University of Oklahoma Health Sciences Center; EY020849 and EY012020, M.X.); the SUNY/RF Research Collaboration Fund (X.M., S.J.F., and E.S.); Unrestricted Grants from Research to Prevent Blindness to the Department of Ophthalmology of University at Buffalo (X.M. and S.J.F.) and to the Department of Ophthalmology at SUNY Upstate Medical University (E.S.); Oklahoma Center for the Advancement of Science and Technology (OCAST HR08-149S, D.M.S.); the Lions of Central New York (E.S.); and resources and facilities provided by the Veterans Administration Western NY Healthcare System (S.J.F.). The views expressed herein are not necessarily those of the Veterans Administration. We thank Drs. Jane Johnson and Helena Edlund for kindly providing the anti-Ptfla antibodies, Barbara A. Nagel for expert technical assistance with TEM, and members of the Developmental Genomics Group at the New York State Center of Excellence in Bioinformatics and Life Sciences and the Department of Ophthalmology at the University of Buffalo for helpful discussions.

The authors declare no competing financial interests.

Correspondence should be addressed to Xiuqian Mu, 701 Ellicott Street, Buffalo, NY 14203. E-mail: xmu@buffalo.edu.

DOI:10.1523/JNEUROSCI.0116-13.2013

Copyright $\odot 2013$ the authors $\quad 0270-6474 / 13 / 3313053-13 \$ 15.00 / 0$
During development, all of the retinal cell types originate from a common pool of multipotent progenitor cells (Cepko et al., 1996). Both intrinsic and extrinsic pathways are involved in the process, and gene regulation is a major intrinsic mechanism controlling the formation of individual retinal cell types (Agathocleous and Harris, 2009; Xiang, 2013). However, a comprehensive understanding of the underlying gene regulatory pathways is still lacking. Many key regulators remain to be identified, and their functions to be characterized. Here we report the results of our investigation into the roles of a novel regulator, Onecut 1 (Oc1; also known as Hnf6), in retinal development, and its function in the formation of HCs.

HCs are second-order neurons that process visual information laterally within the outer plexiform layer (OPL; Thoreson and Mangel, 2012). They receive input from rod and cone photoreceptors (Cervetto and MacNichol, 1972), and provide inhibitory input to photoreceptors and bipolar cells (Wu, 1992). HCs form during the first wave of retinal neurogenesis, which starts at embryonic day 11 (E11) and peaks at E14.5 in the mouse (Young, 1985; Cepko et al., 1996). Several transcription factors, including FoxN4, Prox1, Ptfla, Lim1, Sall3, AP- $2 \alpha$, and AP- $2 \beta$, have been reported to play roles in HC development (Dyer et al., 2003; Li et al., 2004; Fujitani et al., 2006; Nakhai et al., 2007; Pochè et al., 2007; de Melo et al., 2011; Bassett et al., 2012). Nevertheless, it 
remains unclear how and when fated HCs arise from the retinal progenitor pool and what factors determine the $\mathrm{HC}$ fate.

Ocl belongs to the onecut transcription factor family, members of which have been shown to regulate development of the liver, pancreas, and the immune system (Lemaigre et al., 1996; Samadani and Costa, 1996; Landry et al., 1997; Jacquemin et al., 2003; Margagliotti et al., 2007; Furuno et al., 2008), as well as the CNS (Francius and Clotman, 2010; Espana and Clotman, 2012a, b; Roy et al., 2012; Wu et al., 2012). All three mouse Onecut factors (Oc1, Oc2, and Oc3) are also expressed in the developing retina, but only $\mathrm{Oc1}$ and $\mathrm{Oc} 2$ are expressed at high levels (Wu et al., 2012). To investigate the role of Ocl in retinal development, we specifically inactivated $O c 1$ in the developing mouse retina by Cre-mediated recombination. Our results indicate that $\mathrm{Ocl}$ is essential for HC development and determines HC fate in collaboration with Ptfla. Further, we show that when the number of $\mathrm{HCs}$ is severely reduced, the synaptic connections between photoreceptors and bipolar cells in the OPL are abnormal, and that photoreceptors degenerate as the mice age, suggesting a previously unrecognized role of HCs in maintaining synaptic structure, photoreceptor viability, and retinal integrity.

\section{Materials and Methods}

Animals. The floxed $O c 1$ allele $\left(O c 1^{\text {flox }}\right)$ and the Six3-cre transgenic line have been described previously (Furuta et al., 2000; Zhang et al., 2009). The Ptfla ${ }^{-}$(Ptfla $a^{\text {cre }}$ ) mice (Fujitani et al., 2006) were obtained from MMRRC-UNC (Stock number: 000435-UNC). All lines were maintained in C57BL/6 $\times 129$ mixed background. All procedures using mice conform to the U.S. Public Health Service Policy on Humane Care and Use of Laboratory Animals and were approved by the Institutional Animal Care and Use Committees of Roswell Park Cancer Institute and University at Buffalo.

Immunofluorescence labeling. Immunofluorescence labeling of frozen retinal sections followed our previously published procedure (Wu et al., 2012). Whole-mount immunostaining of the retina followed a protocol used by Kay et al., (2011). In cases where the primary antibody was from mouse, the sections were first blocked by donkey anti-mouse IgG Fab fragment (50 $\mu \mathrm{g} / \mathrm{ml}$ Jackson ImmunoResearch, 715-007-003) to reduce the background from endogenous mouse IgG. The sources and dilutions of antibodies against Pou4f2, HA tag, Onecut 1 (Hnf6), Onecut 2, calbindin, Isl1, Lim1 (mouse), Chx10, Pax6, syntaxin I, NF160, protein kinase $\mathrm{C} \alpha(\mathrm{PKC} \alpha)$, FoxN4, and rhodopsin were as reported by us in previous publications (Li et al., 2004; Mu et al., 2005, 2008; Fu et al., 2006, $2009 \mathrm{Wu}$ et al., 2012). Other antibodies used in these studies include: rabbit anti-Lim1 (1:100; Millipore, AB3200), mouse anti-Prox1 (1:200; Millipore, MAB5654), rabbit anti-Sox9 (1:500; Millipore, AB5535), rabbit anti-Pgp9.5 (1:500; Millipore, AB1761), rabbit anti-cone arrestin (CAR) (1:500; Millipore, AB15282), guinea pig anti-doublecortin (Dcx) (1:500; Millipore, AB2253), guinea pig anti-Ptf1a (1:400; Dr. Jane Johnson, Utah Southwestern Medical Center), rabbit anti-Ptfla (1:800; Dr. Helena Edlund, Umeå University), mouse anti-Bassoon (1:100; Enzo Life Sciences, ADI-VAM-PS003-D), and rabbit anti-GFP (1:150; Abcam, AB290). Alexa Fluor 488-conjugated and Alexa Fluor 546-conjugated secondary antibodies against IgGs of various species (Invitrogen) were used at 1:800 dilution. When necessary, the nuclei were counterstained with propidium iodide. Images were collected using a Leica TCS SP2 confocal microscope. To collect whole-mount images, image stacks of equal thickness in the $z$-plane were collected for both wild-type and Oc1-null retinas.

Cell counting. Cell counting was performed as described previously (Mu et al., 2005; Wu et al., 2012). Briefly, retinal sections from desired developmental stages were stained with cell type-specific antibodies as described above, counterstained with propidium iodide, and total cells and marker-positive cells were counted on arbitrary retinal section lengths in the central retinal regions. For each cell type, three to four sections from at least two individual animals were counted. To count cells in the whole-mount retinas, cells from corresponding regions of wild-type and Oc1-null retinas were counted. Statistical significance was assessed by unpaired Student's $t$ test, assuming equal variance with a two-tailed distribution; the threshold for statistical significance was set at $p<0.05$.

Histology. Tissue processing and hematoxylin and eosin (H\&E) staining of mouse retinal sections were performed as described previously (Mu et al., 2008). Briefly, eyes from wild-type and mutant mice were enucleated, fixed in buffered mixed aldehydes (3\% paraformaldehyde and $2 \%$ glutaraldehyde, in PBS, pH 7.4), and embedded in paraffin. The tissues were then sectioned ( $7 \mu \mathrm{m}$ in thickness), dewaxed, and stained with $\mathrm{H} \& \mathrm{E}$ sequentially. Images were collected using a Nikon Eclipse 80i microscope using a SPOT RT3 digital camera (Diagnostic Instruments).

In utero electroporation. DNA constructs expressing Oc1 or Ptfla under the CAG promoter were made by replacing the GFP coding sequence with Oc1 or Ptfla full-length cDNA in the previously reported pCAGGFP plasmid (Addgene; Plasmid 11150) (Matsuda and Cepko, 2004). In utero electroporation was performed following a previously published procedure (Petros et al., 2009). Briefly, pregnant female mice were anesthetized at E13.5 using vaporized isoflurane (2-5\%) mixed with oxygen. A $2 \mathrm{~cm}$ vertical incision was made on the midline of the abdomen to expose the uterine horns, and $0.5 \mu \mathrm{l}$ of DNA solution $(2.5 \mu \mathrm{g} / \mu \mathrm{l}$ of each DNA construct, $0.5 \mu \mathrm{g} / \mu \mathrm{l}$ pCAG-GFP, and $0.025 \%$ Fast Green Dye) was injected through the uterine wall and amniotic sac into an embryonic retina with a fine-tipped micropipette. After injection, wet electroporation paddles were placed on the sides of the embryo head, and five $40 \mathrm{~V}$, $50 \mathrm{~ms}$ square pulses were delivered by an electroporation device (ECM 830; Harvard Apparatus). The embryonic chain was then placed back into the abdominal cavity, the peritoneum and the skin were then closed, and the embryos were allowed to develop further to E17.5, and analyzed by immunofluorescence.

Transmission electron microscopy. Mouse eyes were fixed with buffered mixed aldehydes, osmicated, serially dehydrated, and embedded in plastic resin in preparation for transmission electron microscopy (TEM) analysis, as described previously (Ding et al., 2004; Stricker et al., 2005). Thin sections $(600-800 \AA)$ were obtained with an ultramicrotome (Reichert-Jung Ultracut E Microtome; American Instruments) using a diamond knife, collected onto copper 75/300 mesh grids (Electron Microscopy Sciences), and stained with $2 \%(\mathrm{w} / \mathrm{v})$ uranyl acetate and Reynolds' lead citrate. Sections were viewed using a JEOL 100CX electron microscope (JEOL) at an accelerating voltage of $60 \mathrm{keV}$, and digital images were collected and stored on a computer for subsequent viewing and analysis.

Electroretinogram recording. Electroretinogram (ERG) recording was performed as previously reported (Umino et al., 2012). In brief, darkadapted mice were placed in a light-proof cage and anesthetized with 60 $\mathrm{mg} / \mathrm{kg}$ pentobarbital (Nembutal; Lundbeck). Pupils were dilated with a couple of drops of $1 \%$ tropicamide, corneas were kept moist with $0.3 \%$ glycerine $/ 1.0 \%$ propylene glycol, and body temperature was maintained at $37^{\circ} \mathrm{C}$ with a heating pad. ERGs were recorded using the Espion E2 system and a ColorDome Ganzfeld stimulator (Diagnosys) in response to brief LED flashes $(520 \mathrm{~nm}$ ). The scotopic (dark-adapted) b-wave amplitude was measured from the a-wave trough to the peak of the cornealpositive b-wave. For light-adapted ERG, retinas were exposed to a steady adapting background $(520 \mathrm{~nm})$ of $10 \mathrm{~cd} / \mathrm{m}^{2}$. The number of photoisomerizations/ rod/ $\mathrm{s}$ produced by the background was estimated as described previously (Umino et al., 2012).

\section{Results}

\section{Retina-specific deletion of $\mathrm{Ocl}$}

To delete $O c 1$ specifically in the developing retina, we crossed the $O c 1^{f l o x}$ line with the Six3-Cre transgenic mice. The Oc1 $1^{\text {flox }}$ allele has two loxP sites flanking the first exon, which encodes the N-terminal part of the protein including the "cut" domain, which is the main DNA binding domain. Cre-mediated recombination leads to the deletion of this exon and results in a null allele (Zhang et al., 2009). The Six3-Cre transgene is specifically expressed in the neural retina, starting from $\mathrm{E} 9$, a time when retinal neurogenesis has yet to begin and $O c 1$ expression in the retina has not yet 


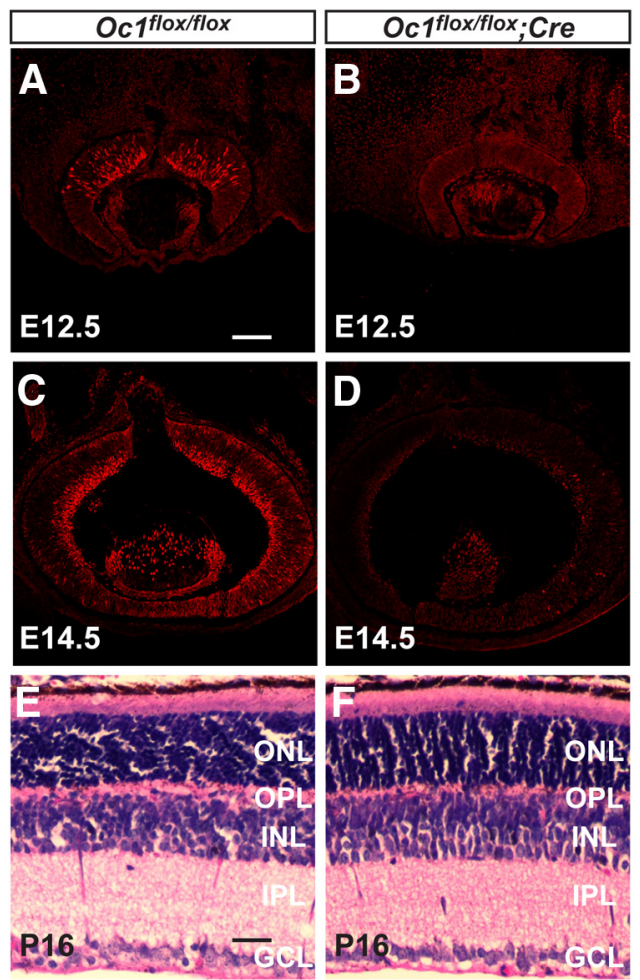

Figure 1. $\quad 0 c 1$ is efficiently deleted in the retina by Six3-Cre and its deletion leads to defects in the OPL. $\boldsymbol{A}-\boldsymbol{D}$, Immunofluorescence labeling using anti-0c1 antibodies on $0 \mathrm{Cl}^{\text {flox/flox }}$ and $\mathrm{OCI}^{\text {flox/flox; }}$;ix3-Cre (OC1-null) retinal sections from E12.5 and E14.5. OC1 shows identical expression patterns in $0 \mathrm{C}^{\text {flox/flox }}$ retinas to those previously reported in wild-types at E12.5 $(\boldsymbol{A})$ and $\mathrm{E} 14.5$ (C). In OC flox/flox $_{\text {; }}$ Six3-Cre retinal sections, almost no $0 \mathrm{c} 1$ could be detected at both E12.5

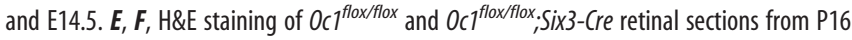
mice. Compared with the wild-type control retina, the OPL of the Oc1-null retina is greatly reduced. All other cell layers are comparable to those in the control retina. Scale bars: (in $\boldsymbol{A}$ ), $\boldsymbol{A}-\boldsymbol{D}, 150 \mu \mathrm{m}$; (in $\boldsymbol{E}), \boldsymbol{E}, \boldsymbol{F}, 75 \mu \mathrm{m}$.

initiated (Cepko et al., 1996; Furuta et al., 2000; Wu et al., 2012). To examine the efficiency of deletion of Oc1 by Six3-cre, we examined Ocl expression by immunofluorescence on $O c 1^{\text {flox/flox }}$ and Oc1 $1^{\text {flox/flox }}$; Six 3-cre retinal sections at E12.5 and E14.5 (Fig. $1 A-D)$. Whereas Oc1 was readily detectable in control Oc1 flox/flox retinas as previously reported for wild-type retinas (Wu et al., 2012), there was essentially no signal in Oc1 ${ }^{\text {flox/flox }}$; Six 3-cre retinas at either E12.5 or 14.5, indicating that $O c 1$ was efficiently deleted in the developing retina at an early stage. We refer to $O c 1^{\text {flox/flox; }}$ Six3-cre as Oc1-null $\left(\mathrm{Ocl}^{-/-}\right)$hereafter. Adult $\mathrm{Oc1}$-null mice showed no gross health issues and were fertile. Since $O c 1^{\text {flox/flox }}$ mice exhibit the wild-type phenotype, both $O c 1^{\text {flox/flox }}$ and true wild-type littermates were used as controls and will be referred to as wild-type $\left(\mathrm{Ocl}^{+/+}\right)$hereafter. To first assess the consequences of $O c 1$ deletion, we examined postnatal day 16 (P16) retinas histologically (Fig. 1E,F). Retinas from Oc1-null mice exhibited normal cell layer lamination; the outer nuclear layer (ONL), inner nuclear layer (INL), inner plexiform layer (IPL), and ganglion cell layer (GCL) were of similar thickness to the corresponding layers of control retinas, and showed no overt morphological abnormalities. However, the OPL, which is composed of photoreceptor terminals and processes from $\mathrm{HCs}$ and bipolar cells, was markedly reduced and even absent in some locations (Fig. $1 F$ ). Since HCs are the only Ocl-expressing cell type that extends processes into the OPL (Wässle and Boycott, 1991; Masland, 2001; Wu et al., 2012), it was likely that changes in the OPL of the Oc1-null retina reflected effects on HCs.

\section{Effect of $O c 1$ deletion on retinal cell differentiation}

Next, we performed immunofluorescence labeling using cell type-specific markers to examine whether the different retinal cell types formed normally at P16. These markers included rhodopsin (rods; Fig. 2A,B), CAR (cones; Fig. 2C,D), Chx10, and PKC $\alpha$ (bipolar cells; Fig. 2E, F; data not shown), Pax6 (amacrine cells and RGCs; Fig. 2G,H), syntaxin I (amacrine cells; Fig. 2I,J), Sox9 and vimentin (Müller cells; Fig. $2 K-N$ ), Pou4f2 (RGCs; Fig. $2 O, P$ ), and calbindin (HCs and amacrine cells; see Fig. $4 A, B$ ). We observed no obvious changes in the locations and numbers of rods, cones, bipolar cells, Müller cells, amacrine cells, or RGCs in Oc1-null retinas compared with wild-type retinas (Fig. 2A-P). All these cell types had normal morphology, and cell counting confirmed that their individual proportions to the total cell number were not impacted by deletion of Ocl (Fig. 2Q). However, consistent with the observed thinning of the OPL in Oc1-null retinas (Fig. $1 F$ ), the number of HCs detected by calbindin immunostaining was significantly reduced (Figs. 2, 4B; see details below).

Since Oc1 is also highly expressed in nascent RGCs and their precursors (Wu et al., 2012), we examined the expression of six RGC markers at E14.5, a time of peak RGC production, to ascertain whether or not RGCs were affected by deletion of Oc1 (Fig. 3). These markers included Pou4f2 (Fig. $3 A, B$ ), Isl1 (Fig. 3C,D), Oc2 (Fig. $3 E, F$ ), NF160 (Fig. 3G,H), Dcx (Fig. $3 I$, J), and Pgp9.5 (Fig. $3 K, L$ ). With the exception of Oc2, these markers showed no change in their expression patterns and levels in Oc1-null retinas compared with wild-type controls. In the case of Oc2, whereas its expression pattern did not change, there was a marked increase in its expression level in the GCL (Fig. $3 E, F$ ), suggesting that Oc2 may compensate and function redundantly with Oc1. These observations indicate that deletion of $\mathrm{Ocl}$ did not affect the development and maintenance of RGCs. Therefore before P16, when retinal cell generation is essentially complete (Young, 1985; Cepko et al., 1996), only HCs were affected in the Oc1-null retinas.

\section{Oc1 is required for $\mathrm{HC}$ development}

Calbindin is expressed by HCs, which are located in the INL adjacent to the OPL, and by subsets of amacrine cells and RGCs found in the inner INL and GCL, respectively (Fig. 4A; Pochet et al., 1989). Deletion of $O c 1$ affected HCs, but not amacrine cells at P16 (Fig. 4B). The number of HCs in Ocl-null retinas was reduced by $75 \%( \pm 10.2 \%, n=3)$ compared with wild-type retinas (Fig. 2Q). To further investigate $\mathrm{HC}$ deficiency in the Ocl-null retina, we examined the expression of several other $\mathrm{HC}$-specific markers, including Oc2, Lim1, Pgp9.5, and NF160 (Fig. 4C-J). Consistent with the reduction in calbindin-positive HCs (Fig. $4 B$ ), the numbers of HCs positive for these other markers were similarly reduced in the $O c 1$-null retina (Fig. $4 D, F, H, J$ ). In addition to HCs, NF160 is expressed in RGCs (Fig. 4G), while Pgp9.5 is expressed in amacrine cells (Fig. 4I), but the levels of expression of these genes in non-HCs did not change in Oc1-null retinas (Fig. $4 \mathrm{H}, \mathrm{J})$. These data confirmed that $\mathrm{Ocl}$ deletion selectively affected HCs and resulted in the loss of the majority of HCs. To further examine the residual HCs in Oc1-null retinas, we double immunolabeled for Oc1 and either calbindin or Oc2 (Fig. $4 A-D)$. As we reported previously, Oc1 and Oc2 are expressed in all HCs of wild-type retinas, and they completely overlap with calbindin in these cells (Fig. 4A,C; Wu et al., 2012). In Oc1-null retinas, the vast majority $(>95 \%)$ of residual HCs were negative for Oc1 (Fig. 4B,D), but all were positive for Oc2 (Fig. 4D; data not shown). These results suggest that $O c 2$, instead of undeleted Ocl due to inefficient Cre activity, was responsible for the residual HCs. To further confirm these findings and to assess the 
distribution and morphology of the remaining HCs, we performed wholemount staining of HCs with anti-Lim1 and anti-calbindin antibodies (Fig. $4 K-$ $P)$. The same degree of HC loss (80.5 \pm $0.3 \%, n=4$ ) was observed in the Oc1-null retinas (Fig. $4 L, N$ ) compared with the wild-type retinas (Fig. $4 K, M$ ). In wildtype retinas, HCs are distributed in a nonrandom mosaic pattern (Fig. $4 K, M$; Cook and Chalupa, 2000). In the Oc1-null retinas, this mosaic distribution pattern was maintained for the remaining HCs, although the distances between neighboring HCs became larger due to reduction of HC numbers (Fig. $4 L, N$ ). In addition, immunostaining of calbindin revealed that the $\mathrm{HC}$ processes were longer and thicker in the $O c 1$-null retinas than those in the wild-type, but the overall density of $\mathrm{HC}$ processes was markedly reduced (Fig. $4 M-P)$, indicating that the remaining HCs attempted to fill in the increased space between them with their processes, but unsuccessfully.

The loss of HCs in the mature Oc1-null retina could be due to either initial failure of HC birth or defective differentiation/ maintenance after their birth. To distinguish between these two possibilities, we examined $\mathrm{HC}$ formation at E14.5 by immunofluorescence staining for Lim1 and Prox1 (Dyer et al., 2003; Pochè et al., 2007). These markers are expressed in newly born HCs, which migrate basally to the boundary between the neuroblast layer (NBL) and the GCL in wild-type retinas by E14.5 (Fig. 5A,C,E,G). Prox1 is also expressed in retinal progenitor cells (Fig. 5E, G; Dyer et al., 2003) at E14.5, but its expression in newly formed $\mathrm{HCs}$ is much higher and colocalizes with Oc1 (Fig. $5 E, G$ ). In E14.5 Oc1-null retinas, the number of $\mathrm{Lim}^{+}{ }^{+} \mathrm{HC}$ precursors was reduced by $85 \%( \pm 3.9 \%, n=3)$ compared with wild-type controls (Fig. $5 A-D$ ). The numbers of HC precursors strongly expressing Prox1 showed a similar reduction (Fig. 5E-H). Thus, the loss of HCs in E14.5 Oc1-null retinas was comparable to that in mature retinas. The deficiency of $\mathrm{HC}$ formation continued at E17.5 (Fig. $5 I-P)$. At this stage, HCs normally are scattered through the NBL while migrating apically to their final destination, and more $\mathrm{HC}$ marker genes begin to be expressed (Fig. 5I, K, M, O). Examination of some of these markers, including Lim1, Oc2, Prox1, and NF160 in Oc1-null retinas, showed that the numbers of HCs remained at $\sim 15 \%$ of those in wild-type retinas (Fig. $5 I-P)$. The few remaining HCs migrated normally and all expressed Oc2 (Fig. $5 L$ ), but very few expressed Oc1 (Fig. $5 N, P$ ), further supporting the idea that $O c 2$ was responsible for the formation of these residual HCs. These data indicated that HC de-
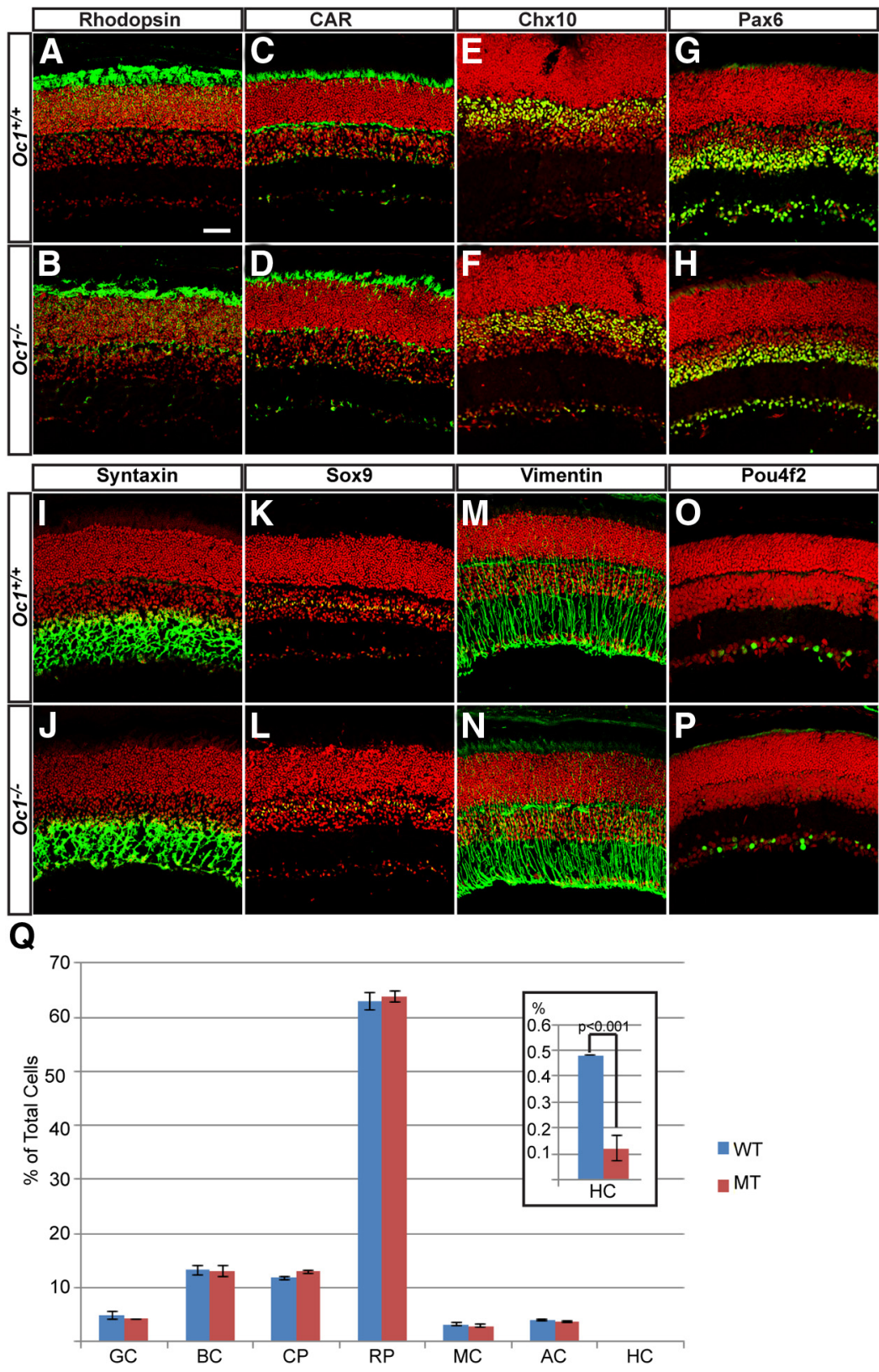

Figure 2. Deletion of $0 c 1$ does not affect formation of photoreceptors, bipolar cell, amacrine, ganglion, or Müller cells. Immunofluorescence labeling for cell type-specific markers was used to examine the formation of six retinal cell types in wild-type

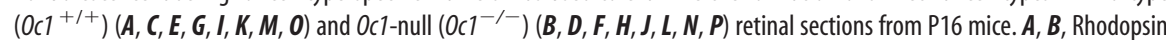
staining for rod photoreceptors. $C, D$, CAR staining for cone photoreceptors. $E, F$, Chx10 staining for bipolar cells. $G, H$, Pax 6 staining for amacrine cells and retinal ganglion cells. $I, J$, Syntaxin I staining for amacrine cells. $K, L$, Sox9 staining for Müller cells. $M, N$, Vimentin staining for Müller cells. $\mathbf{O}, \boldsymbol{P}$, Pou $4 \mathrm{f} 2$ staining for ganglion cells. $\boldsymbol{A}-\boldsymbol{P}$, Green is the cell-type marker and red is propidium iodide (nuclear) staining. Scale bar: (in $\boldsymbol{A}) \boldsymbol{A}-\boldsymbol{P}, 75 \mu \mathrm{m}$. $\boldsymbol{Q}$, The proportion of the total retinal cell population accounted for by each cell type was calculated and statistical significance was determined using Student's test ( $p<0.05$ criterion level for significance). There were no significant differences in the numbers of ganglion cells (GC), bipolar cells $(B C)$, cone photoreceptors (CP), rod photoreceptors (RP), Müller cells (MC), or amacrine cells (AC) between wild-type and Oc1-null retinas. However, there were significantly fewer HCs (Fig. 4) in the Oc1-null retinas compared with wild-type retinas $(p<0.001)$.

ficiency in Oc1-null retina occurred at very early stages of development, with a failure of HC differentiation. To confirm this, we performed terminal deoxynucleotidyl transferasemediated biotinylated UTP nick end labeling (TUNEL) assay to detect apoptotic cells in wild-type and Oc1-null retinas at E14.5, E17.5, and P0, which span the time window for HC formation, and observed no change in apoptosis in Oc1-null retinas compared with wild-type controls (Fig. 5Q-V). Thus increased apo- 

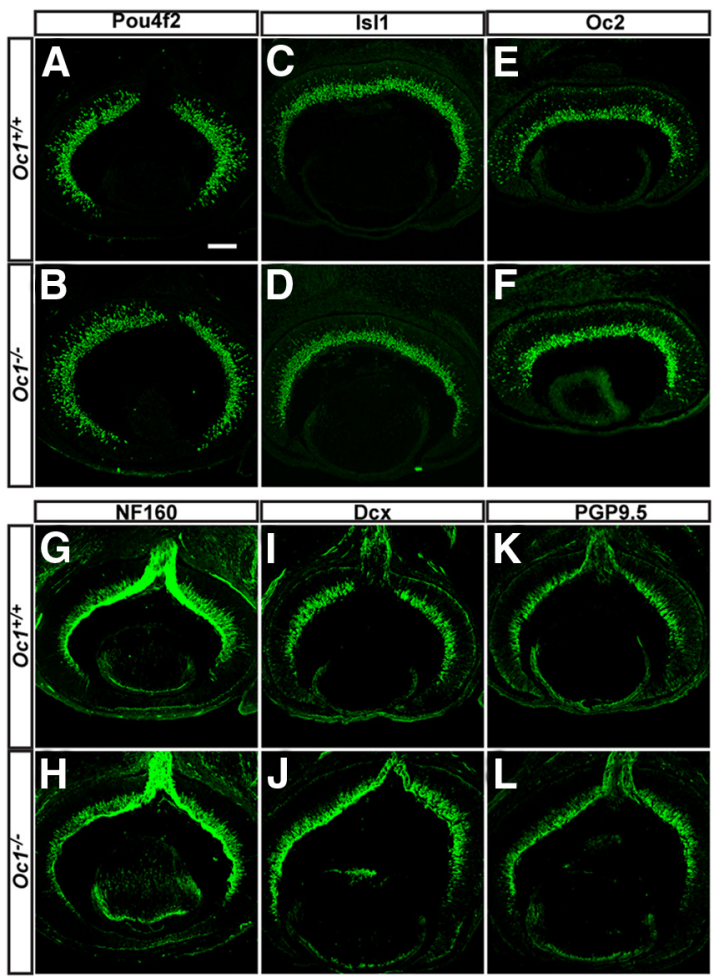

Figure 3. RGC development is not affected in $\mathrm{OC}^{-1-}$ Retina. Six $\mathrm{RGC}$ markers were examined in wild-type $\left(O C 1^{+/+}\right)(A, C, E, G, I, K)$ and $O C 1$-null $\left(O C 1^{-/-}\right)(B, D, F, H, J, L)$ retinal

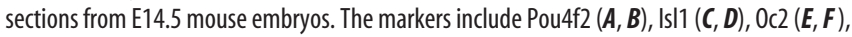
$\operatorname{NF160}(\boldsymbol{G}, \boldsymbol{H}), \operatorname{Dcx}(\boldsymbol{I}, \boldsymbol{J})$, and Pgp9.5 $(\boldsymbol{K}, \boldsymbol{L})$. Except for 0c2, all other markers show no changes in either the levels or patterns of expression in Oc7-null retinas compared with wild-type controls. The expression pattern of 0 c2 does not change in 0c1-null retinas, but its level is increased $(\boldsymbol{F})$. Scale bar, (in $\boldsymbol{A}) \boldsymbol{A}-\boldsymbol{L}, 150 \mu \mathrm{m}$.

ptosis was not the cause of HC loss in Oc1-null retinas. Together these data strongly suggest that in $O c 1$-null retinas, the majority of HCs failed to form during development.

Oc1 is downstream of FoxN4, but acts in parallel with Ptf1a in $\mathrm{HC}$ genesis

Our finding that $\mathrm{Ocl}$ was required for $\mathrm{HC}$ genesis, and that expression of Prox1 and Lim1 were dependent on Oc1, suggested that Oc1 functions upstream of Prox 1 and Lim 1 during $\mathrm{HC}$ development. To further decipher the underlying gene regulatory cascade, we examined the relationship of Ocl to FoxN4 and Ptfla, two transcription factors that are also essential for the HC lineage (Li et al., 2004; Fujitani et al., 2006; Nakhai et al., 2007).

We focused our analysis on E14.5, a stage when most HCs are generated (Young, 1985; Pochè et al., 2007). At E14.5, FoxN4 is expressed in a large subset, but not all, of retinal progenitor cells (Fig. 6A,C) and is critical for the formation of HCs and most amacrine cells (Li et al., 2004). Ptfla is also expressed in the NBL at this stage, but there are far fewer Ptfla ${ }^{+}$cells than FoxN4 ${ }^{+}$ cells (Fig. 6E, G, I, K; Fujitani et al., 2006; Nakhai et al., 2007). Oc1 is expressed in both the NBL and GCL at E14.5 (Fig. 6C, G, K, O). Cells expressing $\mathrm{Ocl}$ in the GCL are RGCs since they also express Pou4f2 and Isl1, two RGC markers (Wu et al., 2012), but the identity of Oc1-expressing cells in the NBL at E14.5 has been uncertain, since they generally do not express markers for RGCs or their precursors (Wu et al., 2012). We observed that only a small subset of FoxN4 ${ }^{+}$cells expressed Oc1, while many Oc1 ${ }^{+}$ cells in the NBL were FoxN4 ${ }^{-}$(Fig. 6A,C). FoxN4 expression

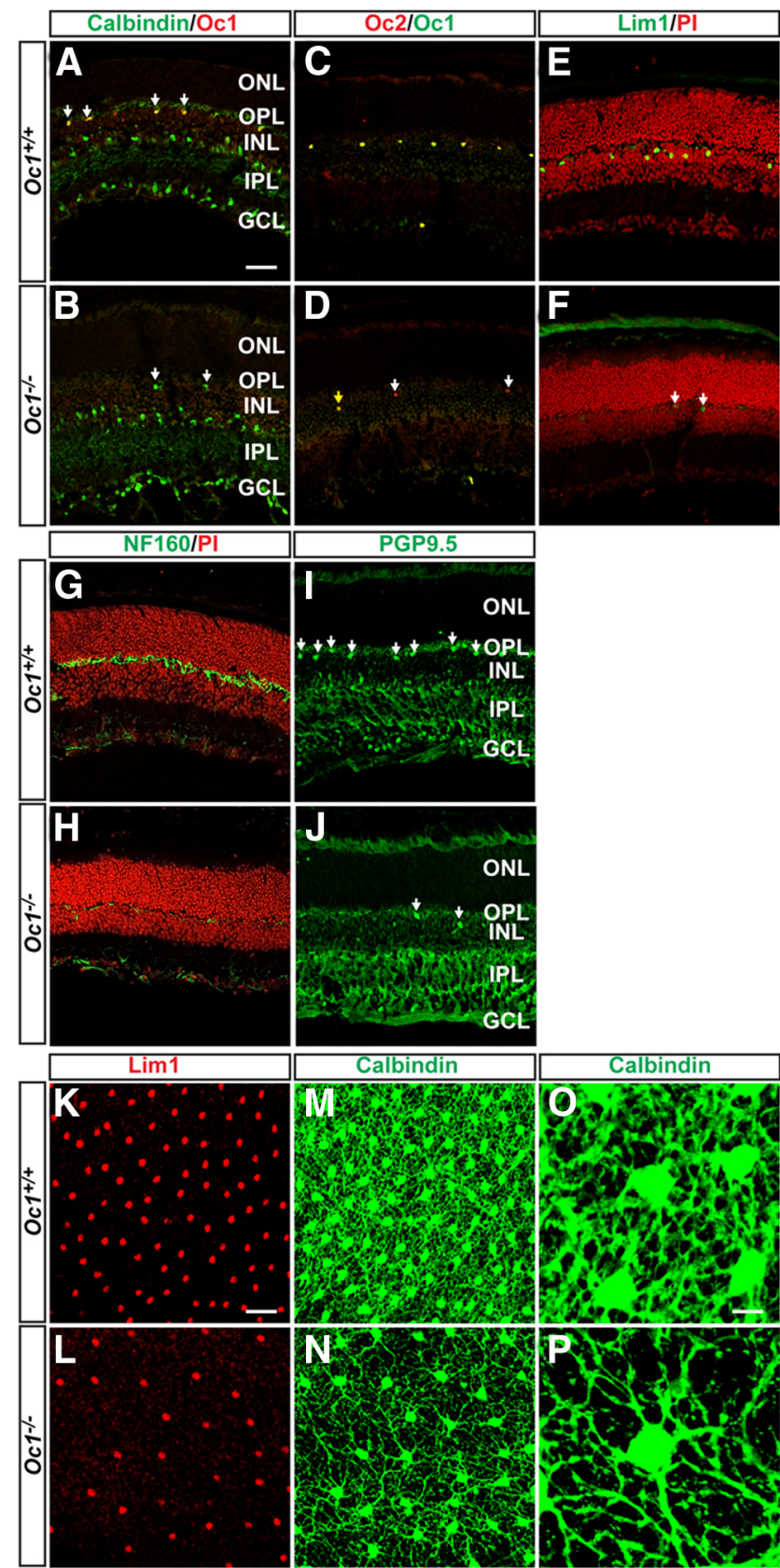

Figure 4. The great majority of HCs are missing in OC1-null retina at P16. A, B, Coimmunolabeling for $0 c 1$ (red) and calbindin (green). In wild-type retina $(\boldsymbol{A})$, cells expressing both calbindin and $0 \mathrm{C} 1$ (arrows) are $\mathrm{HCs}$, and those expressing only calbindin in the INL and $\mathrm{GCL}$ are amacrine cells and RGCS. In Oc1-null retinas, very few $\mathrm{HCs}$ remain and are 0c1-negative (B arrows). Amacrine cells and RGCs are not affected (B). C, D, Colabeling for $0 c 1$ (red) and $0 c 2$ (green). Both are expressed in all HCs in the wild-type retina (C). In Oc1-null retina, only very few $\mathrm{HCs}$ remain, as indicated by $0 \mathrm{c} 2$ staining $(\boldsymbol{D})$. Although occasional $0 \mathrm{c} 1 / 0 \mathrm{c} 2$ double-positive $\mathrm{HCs}$ are observed (yellow arrow in $\boldsymbol{D}$ ), the vast majority of remaining $\mathrm{HC}$ are negative for $0 \mathrm{c}$, but positive for 0 c2 (white arrows in $\boldsymbol{D}$ ). $\boldsymbol{E}, \boldsymbol{F}$, Immunofluorescence labeling for Lim1, which is expressed only in $\mathrm{HCS}$ in wild-type retina $(\boldsymbol{E})$. Lim $1^{+}$cells (green) were greatly reduced in Oc1-null retinas ( $\boldsymbol{F}$, arrows). $\boldsymbol{G}, \boldsymbol{H}$, Immunolabeling (green) for NF160, which is expressed in HC processes in the OPL (G) and RGCs. The numbers of $\mathrm{HC}$ processes are reduced in the Oc1-null retina $(\boldsymbol{H})$, but there is no change in $\mathrm{RGCS} . \boldsymbol{I}, \boldsymbol{J}$, Staining for Pgp9.5, which is expressed in $\mathrm{HCS}(\boldsymbol{I}$, arrows) and a subset of amacrine cells in wild-type retinas (I). In Oc7-null retinas, Pgp9.5 expression in HCs $(\boldsymbol{J}$, arrows), but not in amacrine cells, was greatly reduced. $\boldsymbol{K}-\boldsymbol{P}$, Wholemount staining of HCs by anti-Lim $1(\boldsymbol{K}, \boldsymbol{L})$ and anti-calbindin $(\boldsymbol{M}-\boldsymbol{P})$. Images were obtained from equivalent regions of wild-type and 0,1 -null retinas. $\mathbf{O}, \boldsymbol{P}$, High-magnification images from anti-calbindin staining to show the processes of HCs. Scale bars: (in $\boldsymbol{A}) \boldsymbol{A}-\boldsymbol{J}, 25 \mu \mathrm{m}$; (in $\boldsymbol{K}$ ) $\boldsymbol{K}-\boldsymbol{N}, 12.5 \mu \mathrm{m}$; (in 0) $\mathbf{0}, \mathbf{P}, 2.125 \mu \mathrm{m}$. 
also showed limited overlap with Ptfla localization; only a subset of FoxN4 ${ }^{+}$cells also expressed Ptfla, while many Ptfla ${ }^{+}$ cells expressed little or no FoxN4 (data not shown). Coimmunolabeling for Oc1 and Ptfla revealed that these two factors were only partially overlapping in their expression, and that many cells in the NBL were positive for Ptfla or Ocl alone (Fig. 6E, $G, I, K$ ).

We then examined how deletion of the gene encoding one transcription factor affected the expression of the others. In Oc1-null retinas, there was no significant change in the expression of either FoxN4 or Ptfla (Fig. $6 B, D, F, H$ ). In FoxN4-null retinas, as reported previously (Fujitani et al., 2006), Ptfla expression was completely abolished (Fig. 6J,L). A marked decrease of $\mathrm{Ocl}^{+}$cells in the NBL, but not in the GCL, also was observed in FoxN4null retinas (Fig. $6 I-L$ ). The dependence of these $\mathrm{Ocl}^{+}$cells on FoxN4 in the NBL indicates that they were likely $\mathrm{HC}$ precursors. These results suggest that $\mathrm{Ocl}$, like Ptfla, functions downstream of FoxN4 in the $\mathrm{HC}$ lineage. Consistent with FoxN4 being upstream of Ptfla, FoxN4 expression does not change in Ptfla-null retinas (Fujitani et al., 2006). Interestingly, we also did not observe any changes in Oc1 expression in the NBL of Ptfla-null retinas (Fig. $6 M-P$ ). Similar to Oc1, Ptfla functions before $\mathrm{HC}$ fate determination, since expression of Lim 1 , an early $\mathrm{HC}$ marker, is already diminished at E14.5 in the Ptfla-null retina (Fig. $6 M-P$ ). These results indicate that, during $\mathrm{HC}$ genesis, FoxN4 functions upstream in a large set of retinal progenitor cells, perhaps as a competence factor. Ocl and Ptfla operate downstream of FoxN4. The observation that many $\mathrm{Ocl}^{+}$or $\mathrm{Ptfla}^{+}$cells were FoxN4 ${ }^{-}$also suggests that FoxN4 expression was extinguished once Ocl or Ptfla was expressed. Although both Ocl and Ptfla are essential for $\mathrm{HC}$ formation, they are expressed in two distinct, but overlapping, sets of cells in the NBL and largely do not regulate each other. Since Ocl and Ptfla are coexpressed in only a small subset of cells, it is possible that one transcription factor can regulate the other in those cells, but this might not be detected readily due to the small size of this cell population. To examine this possibility, we ectopically expressed either Ocl or Ptfla by in utero electroporation, using GFP to track cells that took up the DNA constructs, and then analyzed if one factor could induce the other (Fig. 6Q-T). When Oc1 was ectopically expressed, although $\mathrm{GFP}^{+} \mathrm{Ptf1}{ }^{+}$cells could be detected occasionally, no increase of these double-positive cells was observed compared with controls expressing GFP alone (Fig. 6Q,R). Similarly, when Ptfla was ectopically expressed, there was no induction of $\mathrm{Ocl}$ in the $\mathrm{GFP}^{+}$cells com-

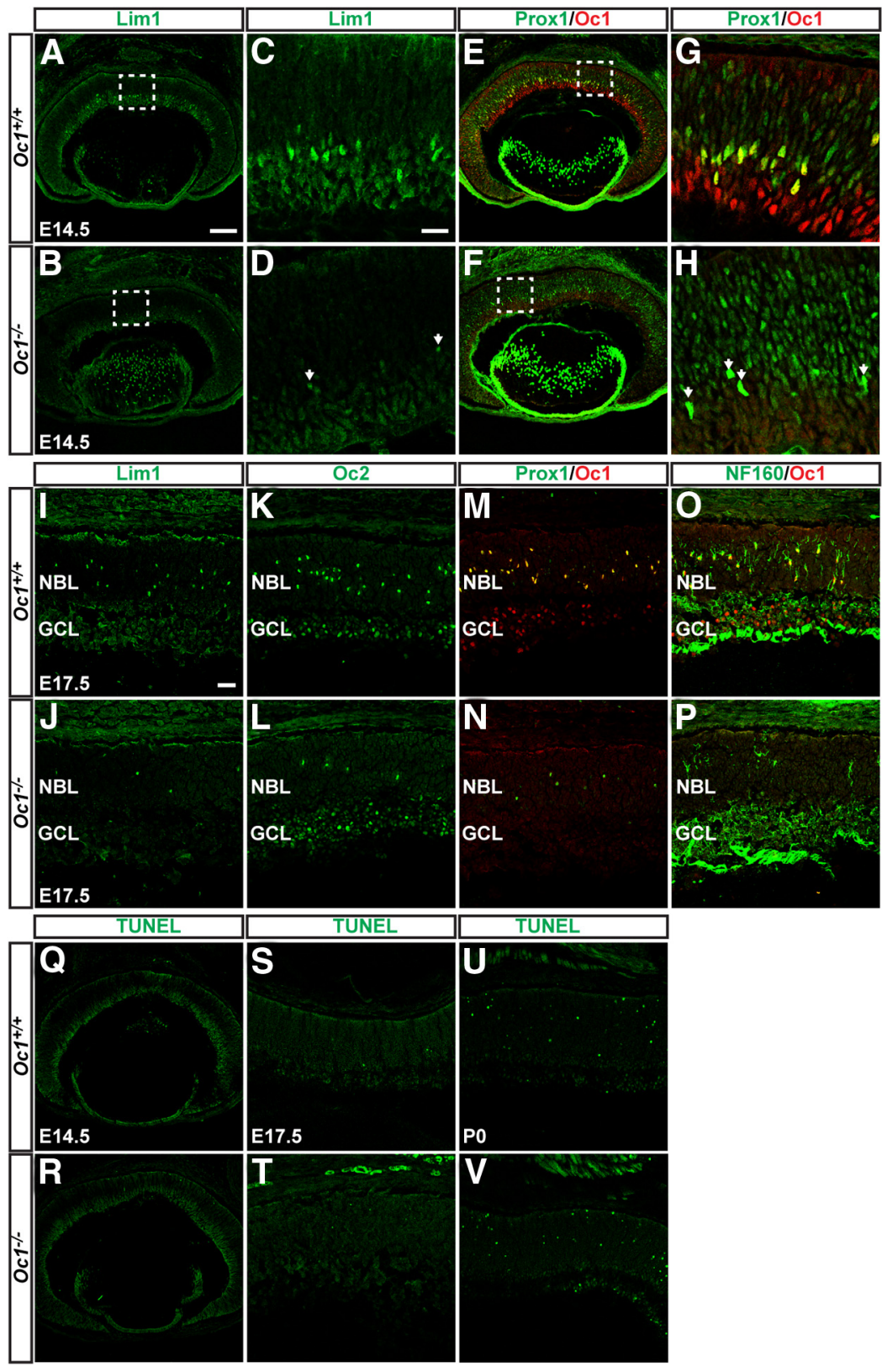

Figure 5. Loss of HCs in OC1-null retinas occurs at early developmental stages. $\boldsymbol{A}-\boldsymbol{H}$, Immunolabeling for Lim 1 and Prox 1 at E14.5. Lim1 and Prox1 are expressed in newly generated HCs located at the boundary between the GCL and the NBL $(A, C, E, G)$. Prox 1 also is expressed in the NBL, but its expression in the newly generated $\mathrm{HC}$ is at a much higher level and overlaps with that of $0 \mathrm{C} 1$ (red in $\boldsymbol{E}$ and $\boldsymbol{G}$ ). In the $0 \mathrm{C} 1$-null retina, the numbers of $\operatorname{Lim}^{+}(\boldsymbol{B}, \boldsymbol{D})$ and $\operatorname{Prox} 1^{+}(\boldsymbol{F}, \boldsymbol{H}) \mathrm{HCs}$ (arrow in $\boldsymbol{D}$ and $\boldsymbol{H}$ ) are greatly reduced. I-P, Immunolabeling for four $\mathrm{HC}$ markers at E17.5. These markers show $\mathrm{HC}$ (s migrating to their final destination scattered throughout the NBL in the wild-type retina $(I-0)$. In the 0 C 7 -null retina $(J-P)$, the numbers of labeled $\mathrm{HC}$ s are greatly reduced, compared with wild-type controls, but these cells still migrate normally. Note that $0 \mathrm{C} 2$ and NF160 are also expressed in the GCL in wild-type retinas $(\boldsymbol{K}, \mathbf{O})$, and that their expression in RGCs does not change in the $0 c 1$-null retina $(\boldsymbol{L}, \boldsymbol{P})$. In addition, all HCs at E17.5 express $0 \mathrm{C} 1$ in wild-type retina $(\boldsymbol{M}, \mathbf{O})$, but few are $0 \mathrm{Cl}^{+}{ }^{+}$in $\mathbf{O} \mathbf{C}$-null retinas $(\boldsymbol{N}, \mathbf{P}) . \mathbf{Q} \mathbf{Q} \mathbf{V}$, TUNEL assay for wild-type and $0 \mathrm{C} 1$-null retinas at $\mathrm{E} 14.5, \mathrm{E} 17.5$, and $\mathrm{P} 0$. No obvious differences were observed between wild-type and mutant retinas at any of the three stages. Scale bars: (in $\boldsymbol{A}) \boldsymbol{A}, \boldsymbol{B}, \boldsymbol{E}, \boldsymbol{F}, \boldsymbol{Q}, \boldsymbol{R}, 150 \mu \mathrm{m}$; (in $\mathbf{C}) \mathbf{C}, \boldsymbol{D}, \mathbf{G}, \boldsymbol{H}, 25 \mu \mathrm{m}$; (in $\boldsymbol{I}) \boldsymbol{I}-\boldsymbol{P}, \mathbf{S}-\boldsymbol{V}, 25 \mu \mathrm{m}$.

pared with the controls (Fig. 6S,T). These results further support the conclusion that Ocl and Ptfla are independent of one other in expression.

\section{Ocl and Ptfla codetermine the HC fate}

Since Ptfla is essential for both HC and amacrine cell formation (Fujitani et al., 2006; Nakhai et al., 2007), yet Oc1 is required only for $\mathrm{HC}$ fate, it is likely that only progenitor cells expressing both 


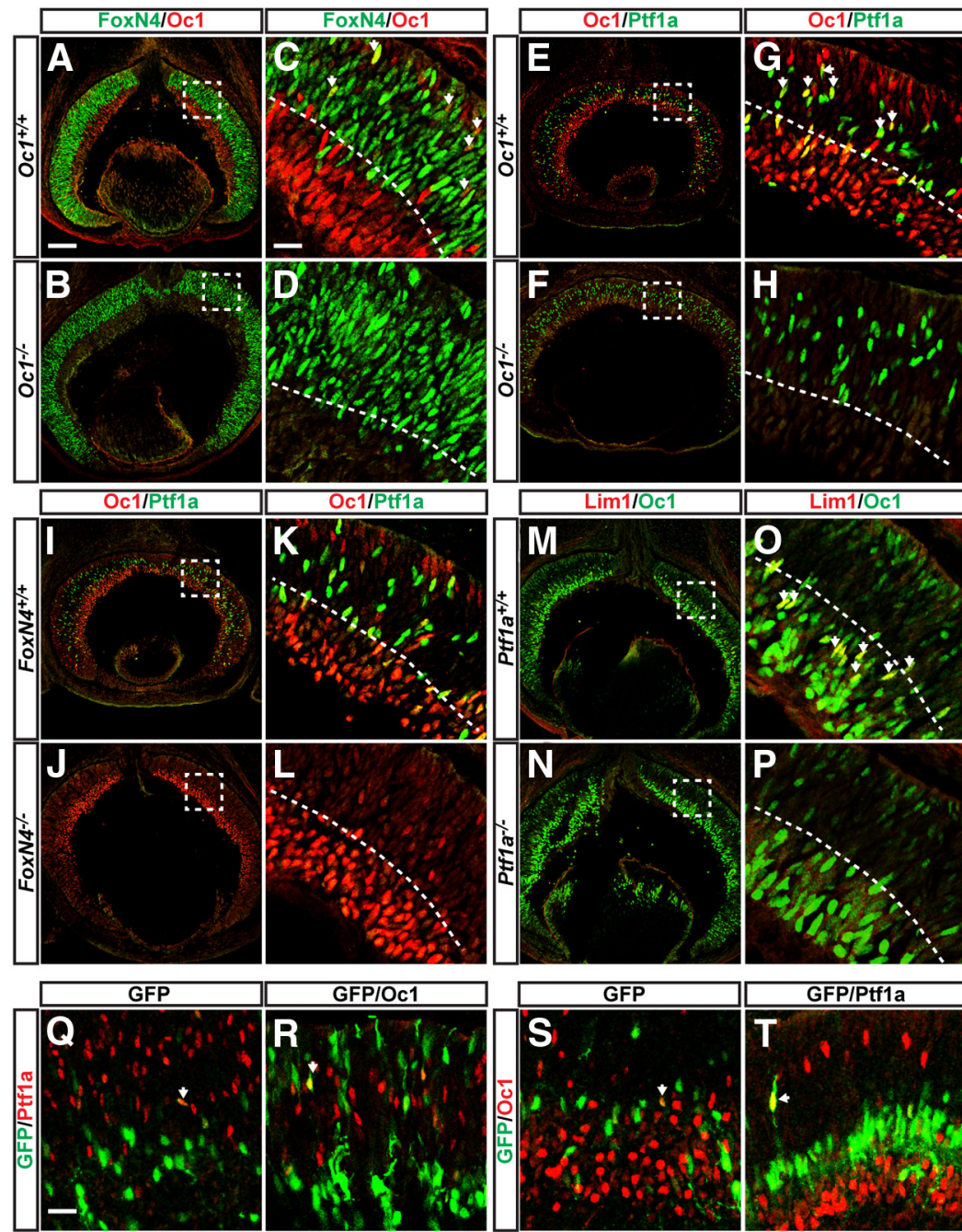

Figure 6. Relationship of $O C 1$ to other transcription factor genes involved in $H C$ genesis. $A-D$, FoxN4 expression pattern overlaps partially with that of $0 \mathrm{C} 1$ in the NBL of E14.5 wild-type retinas, but its expression does not change in $0 \mathrm{C} 1$-null retinas. Arrows $(\boldsymbol{C})$ indicate some Fox $4 / 0$ c1 double-positive cells. $\boldsymbol{E}-\boldsymbol{H}$, The expression pattern of Ptf1a only partially overlaps with that of $0 c 1$ in the NBL and its expression is independent of $0 c 1$. Some Ptf1a/0c1 double-positive cells are indicated by arrows (G). $I-L$, Both $0 \mathrm{C} 1$ and Ptf1a require FoxN4 for expression in the NBL. All Ptfla ${ }^{+}$cells and most $0 \mathrm{c}^{+}{ }^{+}$cells are lost in the NBL of FoxN4-null retinas $(J) . M-P$, Newly formed HCs coexpress Lim 1 and Ptf1a in wild-type retinas (arrows, $\mathbf{0}$ ), but HCs fail to form in Ptf1a-null retinas, as indicated by the absence of Lim $1^{+}$cells $(\boldsymbol{P})$. Expression of $0 \mathrm{c} 1$ in the NBL of Ptf1a-null retinas does not change in $\boldsymbol{P}$. Q $\mathbf{Q} \boldsymbol{T}$, Ectopic expression by in utero electroporation of $0 \mathrm{c} 1$ and Ptf1a did not induce the expression of each other. There was no increase in the number of GFP ${ }^{+} \mathrm{Ptf1a}{ }^{+}$cells when $0 \mathrm{C} 1$ and GFP were expressed $(\boldsymbol{R})$ compared with when only GFP was expressed (Q). Similarly, when Ptfla was expressed $(\boldsymbol{T})$, there was no increase in $\mathrm{GFP}^{+} 0 \mathrm{Cl}^{+}$cells compared with the control (S). Dotted lines demarcate the NBL (top) from the GCL (bottom) in $\mathbf{C}, \mathbf{D}, \mathbf{G}, \boldsymbol{H}, \boldsymbol{K}, \boldsymbol{L}, \mathbf{O}, \boldsymbol{P}$. Arrows in $\mathbf{C}, \mathbf{G}, \mathbf{O}$, and $\mathbf{Q}-\boldsymbol{T}$ indicate double-positive cells. Scale bars: (in $A) A, B, E, F, I, J, M, N, 150 \mu \mathrm{m}$; (in C) C, D, G, $H, K, L, O-T, 25 \mu \mathrm{m}$.

Ptfla and Ocl adopt the HC fate (i.e., Ptfla and Ocl may cooperate to specify $\mathrm{HC}$ fate). To test this hypothesis, we performed in utero electroporation of plasmids expressing Ocl and Ptfla into wild-type retinas. A plasmid-expressing GFP was coelectroporated in all experiments to track cells that had taken up the DNA. Since both $\mathrm{Ptfla}^{+}$and $\mathrm{Ocl}{ }^{+}$cells are sparse in the NBL and are postmitotic, most cells transfected by electroporation should have only expressed the ectopic genes, but not the endogenous Oc1 or Ptfla. If our hypothesis is correct, cells expressing only ectopic Ocl or Ptfla should not adopt the HC fate efficiently, whereas cells transfected with both Oc1 and Ptfla should become HCs. Retinal electroporation was performed on E13.5 embryos, a time when HC formation starts to peak, and the fate of electroporated retinal cells was examined at E17.5 by coimmunofluorescence labeling for GFP and Lim1 or Prox1 (Fig. 7). In retinas that were electroporated with the GFP plasmid alone, only a very small subset (4.7 \pm $1.6 \%, n=4)$ of all $\mathrm{GFP}^{+}$cells were also Lim $1^{+}$(Fig. 7 A,B). The Lim $1^{+}$cells (either $\mathrm{GFP}^{+}$or $\mathrm{GFP}^{-}$) were $\mathrm{HCs}$ that formed as a process of normal development. In retinas electroporated with Oc1 and GFP or Ptfla and GFP constructs, significantly more $\mathrm{GFP}^{+} \mathrm{Lim} 1$ cells were observed in both cases (Fig. $7 E, F, I, J)$. In retinas electroporated with Ptfla and GFP, $13.3 \%( \pm 0.6 \% ; n=4, p<$ $0.001)$ of electroporated cells $\left(\mathrm{GFP}^{+}\right)$ were also $\mathrm{Lim}^{+}$(Fig. 7E,F). In retinas electroporated with Oc1 and GFP, 29.1\% ( $\pm 4.4 \% ; n=4, p<0.001)$ of $\mathrm{GFP}^{+}$cells were Lim $1^{+}$(Fig. $\left.7 I, J\right)$. Critically, when Ocl and Ptfla were electroporated together, most $\mathrm{GFP}^{+}$cells $(70.8 \pm 2.2 \%$; $n=4, p<0.001$ ) were also $\operatorname{Lim}^{+}$(Fig. $7 \mathrm{M}, N)$, indicating these cells adopted the $\mathrm{HC}$ fate. Similar results were observed with Proxl (Fig. $7 C, D, G, H, K, L, O, P$ ). In the control (GFP alone) retinas, $3.6 \pm$ $2.9 \%(n=4)$ of $\mathrm{GFP}^{+}$cells were Prox $1^{+}$ (Fig. 7C,D). In retinas expressing Ptfla and GFP, $2.9 \pm 0.4 \%(n=4)$ of GFP cells were Prox ${ }^{+}$(Fig. 7G,H). In retinas expressing Oc1 and GFP, $6.3 \pm 1.5 \%(n=$ 4) of GFP $^{+}$cells were Prox ${ }^{+}$(Fig. 7 K,L). In retinas expressing both $\mathrm{Ptfla}$ and $\mathrm{Oc} 1$, $62.4 \pm 6.8 \%(n=4)$ of $\mathrm{GFP}^{+}$cells were Prox ${ }^{+}$(Fig. 7O,P). We were unable to further track these cells and examine whether they further developed into mature HCs, since the GFP signals were lost at later stages. This could be due to either the loss of the expression constructs from the cells or loss of the cells themselves since they were ectopically produced. Nevertheless, we conclude that either Ptfla or Ocl is very inefficient when acting alone to promote $\mathrm{HC}$ fate. When both Ptfla and Oc1 were present, however, most cells adopted the HC fate. Therefore, these two factors appear to be not only necessary but also sufficient to direct retinal progenitor cells to adopt the HC fate.

Loss of HCs leads to defects in the synaptic connections in the OPL

The OPL is comprised of photoreceptor terminals, and the processes of HCs and bipolar cells. Photoreceptors form synapses with HCs and bipolar cells in a stereotypical fashion (Olney, 1968; Blanks et al., 1974), but the developmental mechanisms that regulate formation of the complex synaptic interactions remain unclear. Because the first synapses to develop in the OPL are those between photoreceptors and HCs (Olney, 1968; Blanks et al., 1974), an obvious question is what role HCs play in the formation of synapses between photoreceptors and bipolar cells. The deficiency of HCs in Ocl-null retinas allowed us to examine this question directly by TEM. 
In the wild-type retina, rod and cone synaptic terminals stratify in the outer half of the OPL, with the cone terminals residing more proximally (vitread) than most rod terminals. The inner half of the OPL is occupied by the processes of HCs and bipolar cells (Fig. 8A; Olney, 1968; Blanks et al., 1974). We first performed TEM on $\mathrm{P} 30$ retinas. In the Oc1-null retinas, the rod and cone terminals did not exhibit normal stratification and were disorganized (Fig. $8 B-D$ ). Furthermore, photoreceptor terminals in the Oc1-null retina often penetrated deep into the inner portion of the OPL, sometimes extending all the way to the border with the INL (Fig. $8 C$ ). Rod cell bodies and cells from the INL also could be found penetrating into the OPL (Fig. $8 B-D$ ). In wild-type retinas, rods, bipolar cells, and HCs formed the classic "triad" ribbon synaptic complexes (Fig. 8E). However, in Ocl-null retinas, typical triad ribbon synapses were rarely seen, although they possibly could exist at very low frequency (Fig. $8 F-I$ ). However, synaptic ribbons were found in Oc1-null rod terminals, but much more rarely compared with the wild-type, and they typically were not anchored to the plasma membrane, i.e., they appeared to be "free floating" (Fig. 8G,H). Despite this, invaginations of postsynaptic processes sometimes were observed in rod terminals of the Oc1-null retina, although they did not show the classic triad organization (Fig. $8 F$ ). Wild-type cone terminals normally show multiple triadic ribbon synapses organized around short synaptic ribbons, in addition to flat contacts located on the base of the terminal that represent contacts with OFF-cone bipolar cell processes (Fig. 8J). In contrast, in $\mathrm{Ocl}$-null cone terminals, no synaptic ribbons were seen, but invaginations of postsynaptic processes were present and flat contacts between cone terminals and OFF-cone bipolar cell dendrites also were observed (Fig. $8 \mathrm{~K}, L$ ). In addition, extensive tubulovesicular cisternae were observed in both rod and cone terminals (Fig. $8 F, I, M$ ). To rule out the possibility that the observed defects were secondary, we also performed TEM at P16, a stage immediately after completion of synapse formation in the OPL. At P16, HC plexus in the developing OPL was already severely reduced in the Oc1-null retina as show by anti-NF160 staining (Fig. $4 H$ ). Consistently, TEM revealed that the OPL of P16 Oc1-null retina showed defects comparable to those observed at P30, including less frequent and aberrantly positioned ribbons; absence of clear triadic organization to the postsynaptic complexes; and contact of at least some postsynaptic cells with photoreceptor terminals (data not shown).

These results suggest that, in the reduction of HC processes, synaptic ribbons did not anchor properly to the plasma membrane, leading to the loss of the stereotypical triadic organization of postsynaptic processes associated with ribbon synapses of both rods and cones. In contrast, flat contacts between cone terminals and OFFcone bipolar cells still formed. The appearance of the large cisternae in the rod and cone terminals of the Oc1-null retina may reflect a functional change in membrane trafficking in these terminals.
To extend our TEM observations, we immunolabeled synaptic ribbons with anti-Bassoon (Fig. $8 N, Q, T, W$ ) and flat contacts with peanut agglutinin (PNA; Fig. 8O,P, R,S). Consistent with the TEM data, many fewer synaptic ribbons were observed in the OPL of Oc1-null retinas (Fig. 8Q,W), and these ribbons tended to be shorter than those in wild-type retina. In addition, some regions in the OPL were devoid of synaptic ribbons (Fig. 8Q,W). Staining with PNA indicated that flat contacts between cones and OFF-cone bipolar cells were present in the OPL of Oc1-null retinas, but fewer in number, compared with wild-type controls (Fig. 8Q,R).

In addition, we performed immunolabeling with antibodies to $\mathrm{PKC} \alpha$ to visualize rod bipolar cell dendrites in the OPL (Fig. $8 U-Y$ ). In the wild-type retina, rod bipolar cell dendrites contacted rod terminals and were confined within the OPL, as expected (Fig. 8U,V). In the Oc1-null retina, contacts between rod bipolar cell dendrites and photoreceptor terminals were present, but infrequently (Fig. $8 X, Y)$. Furthermore, rod bipolar cell dendrites often showed abnormal sprouting and invasion of the ONL, consistent with disruption of the normal synaptic connections of the OPL (Fig. $8 X, Y$ ). These results indicated that although loss of HCs in the Ocl-null retinas severely disrupted photoreceptor terminals and their synaptic connections in the OPL, some contacts between photoreceptors and bipolar cells persisted.

\section{$\mathrm{HCs}$ are required for retinal integrity and photoreceptor survival}

To further evaluate how loss of HCs affected the function of $O c 1$-null retinas, we performed flash ERG recordings on 5-month-old mice 

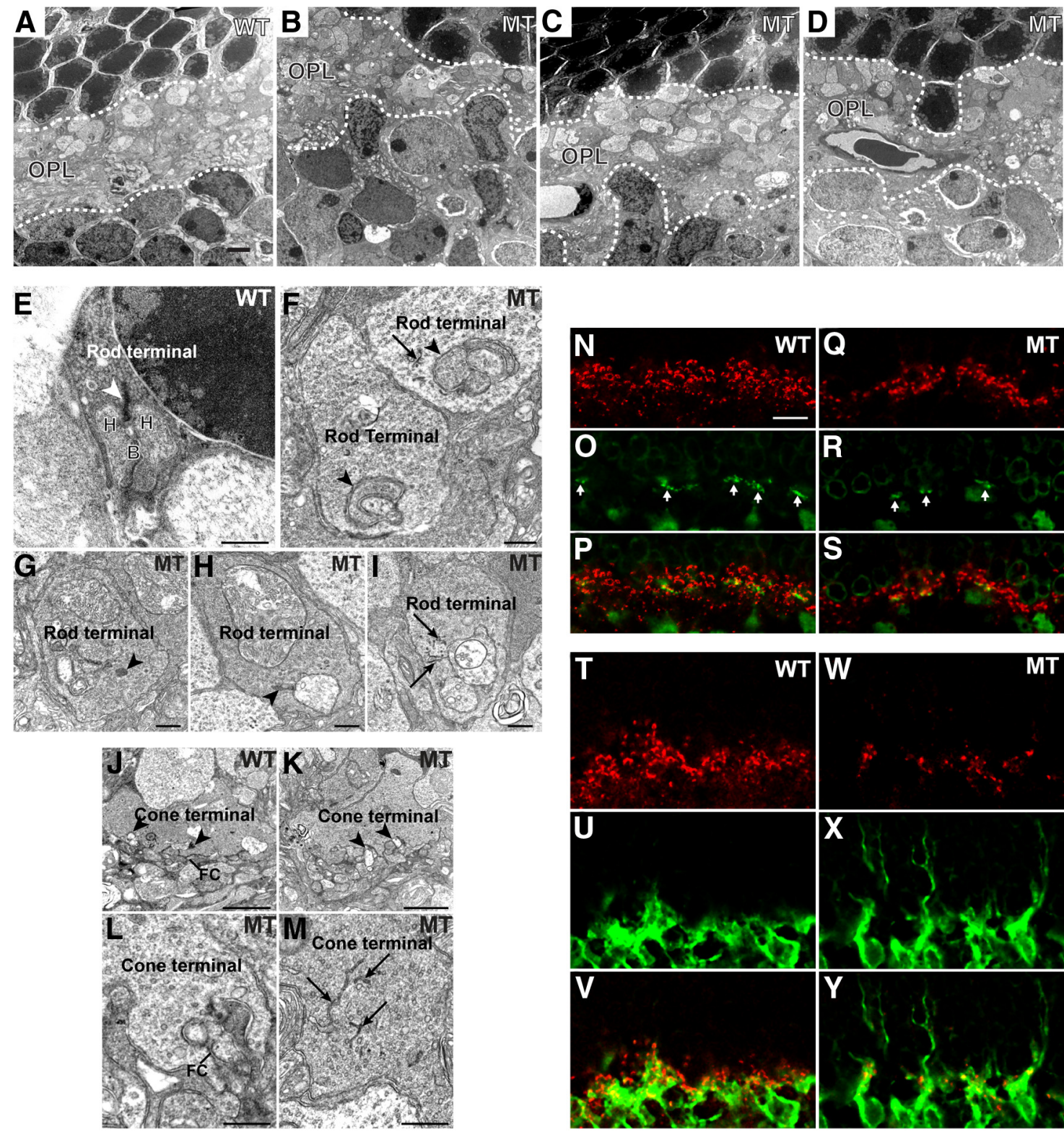

Figure 8. The deficiency of HCs disrupts synaptic ultrastructure and organization of the OPL in Oc1-null retinas. $A-D$, Low-magnification $(5000 \times)$ TEM images of the OPL from P30 wild-type $(W T$; $A$ ) and OC1-null mutant mice $(M T ; B-D)$. The boundaries of the OPL are indicated by dotted lines. $\boldsymbol{A}$, In the WT retina, the OPL is of uniform thickness and is well laminated, with the synaptic terminals of cones and rods localized to the outer (sclerad) portion and processes from secondary neurons localized to the inner (vitread) portion. $\boldsymbol{B}-\boldsymbol{D}$, In the MT retinas, this laminar structure of the OPL is disrupted, with aberrant localization of processes from photoreceptors and bipolar cells. The thickness of the OPL in the MT retina varies from region to region, resulting in irregular boundaries. In addition, intruding bipolar cell ( $\boldsymbol{B}, \mathrm{C}$ and photoreceptor cell bodies (D) can be found in the OPL.E-I,High-magnification (30,000 X) images of rod terminals.J-M, High-magnification images of coneterminals. E, WT rod terminals show normal synaptic ultrastructure with a large synaptic ribbon (arrowhead) in the presynaptic terminal and a postsynaptic "triad" comprised of two HC processes (H) flanking the ribbon laterally and a rod bipolar dendrite (B) occupying the central position. $\boldsymbol{F}$, Rod terminals in the MT retina contain numerous synaptic vesicles but typically do not show synaptic ribbons. However, invaginations containing postsynaptic processes (arrowheads) are present. Arrows point to tubulovesicular cisternae. $\boldsymbol{F}-\boldsymbol{I}$, In rod terminals from MT retinas, "free-floating," amorphous ribbon material (arrowhead in $\mathbf{G}$ ), abnormal synaptic ribbons devoid of associated synaptic vesicles (arrowhead in $\boldsymbol{H}$ ), and tubulovesicular cisternae $(\boldsymbol{I}$, arrows) can be found. $\boldsymbol{J}$, WT cone terminals show invaginations of postsynaptic processes forming multiple synaptic complexes organized around short synaptic ribbons (arrowheads). Flat contacts $(\mathrm{FC})$ are present along the base of the cone terminal. $\boldsymbol{K}, \boldsymbol{L}$, Cone terminals in the MT retina. No synaptic ribbons are present, although invaginations of postsynaptic processes (arrowheads, in $\boldsymbol{K}$ ) and $\mathrm{FC}(\boldsymbol{L})$ are present, but are sometimes ectopically positioned $(\boldsymbol{L})$. $\boldsymbol{M}$, Extensive tubulovesicular cisternae (arrows) in cone terminals in the $M \mathbf{M T}$ retina. $\mathrm{N}-\mathrm{S}$, Colabeling using anti-Bassoon and PNA to visualize synaptic ribbons (red) and FCs (green), respectively, in the OPL of P16WT and MT retinas. In the OPL of the MT retina, the number of synaptic ribbons is markedly reduced, compared with controls; there are also fewer FCs (arrowheads). $T-Y$, Colabeling of synaptic ribbons and rod bipolar cells using anti-Bassoon and anti-PKC $\alpha$, respectively. In the WT retina, processes of rod bipolar cells contact rod terminals but do not extend beyond the $\mathrm{OPL}$ into $\mathrm{ONL}$. In the MT retina, rod bipolar cell dendrites still make contacts with rod terminals, but in someareas projectectopically into the ONL. Scale bars: (in $\boldsymbol{A}) \boldsymbol{A}-\boldsymbol{D}, 2 \mu \mathrm{m} ; \boldsymbol{E}-\boldsymbol{I}, \boldsymbol{L}, \boldsymbol{M}, 500 \mathrm{~nm} ; \boldsymbol{J}, \boldsymbol{K}, 2 \mu \mathrm{m}$; (in $\boldsymbol{N}) \boldsymbol{N}-\boldsymbol{Y}, 10 \mu \mathrm{m}$.

under dark-adapted conditions (Fig. 9A). The corneal-negative a-wave of the ERG provides information about phototransduction (Pugh et al., 1998) and precedes the corneal-positive b-wave that originates from bipolar cell activity in the inner retina (Robson et al., 2004). The a- and b-wave amplitudes recorded from Oc1-null retinas were much smaller than those recorded from control retinas, but the kinetics of the responses, as inferred by the time to peak of the b-wave, was not affected. However, the Ocl-null retinas did not exhibit the robust oscillatory potentials, suggesting that the function of the inner retina also was impaired (Wachtmeister, 1998). The intensity-response functions (Fig. 9B,C) show that the a- and b-waves in Oc1-null retina were uniformly attenuated (by threefold) 
A

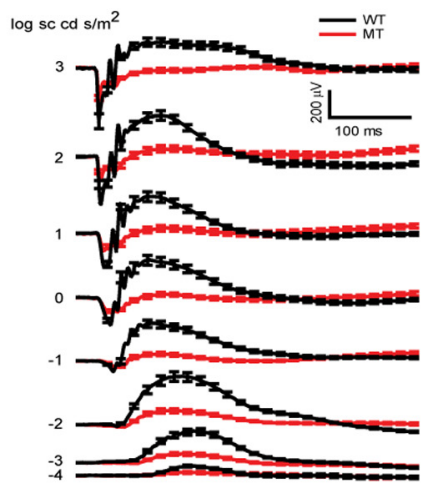

D

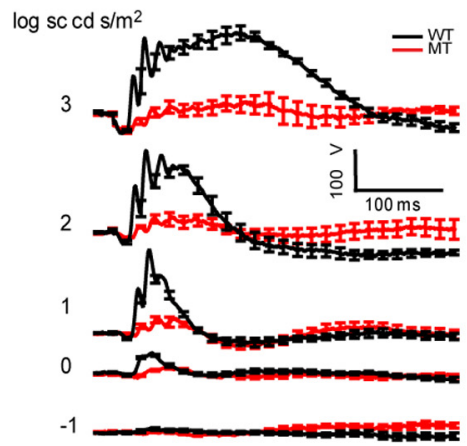

B

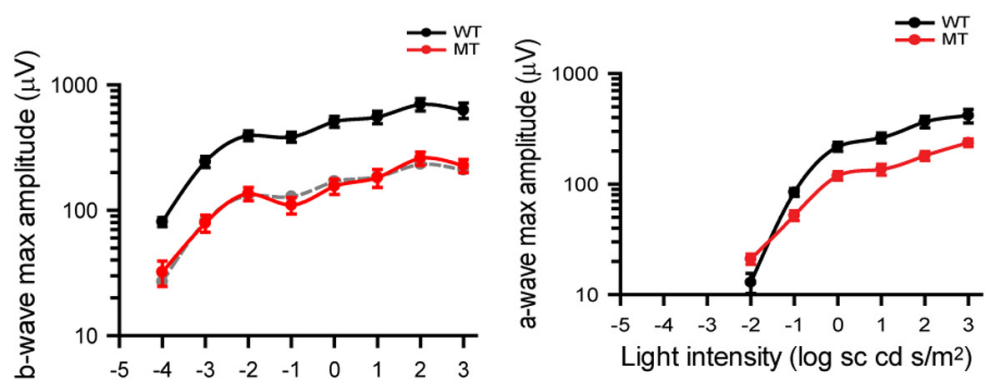

E

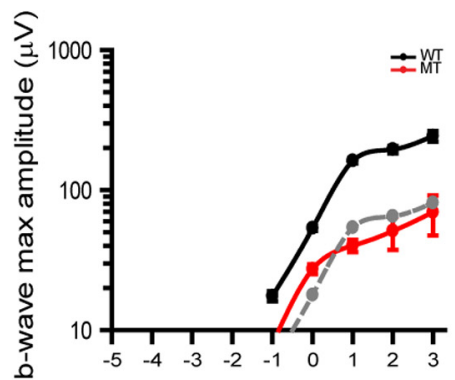

Light intensity $\left(\log \mathrm{sc} \mathrm{cd} \mathrm{s} / \mathrm{m}^{2}\right)$
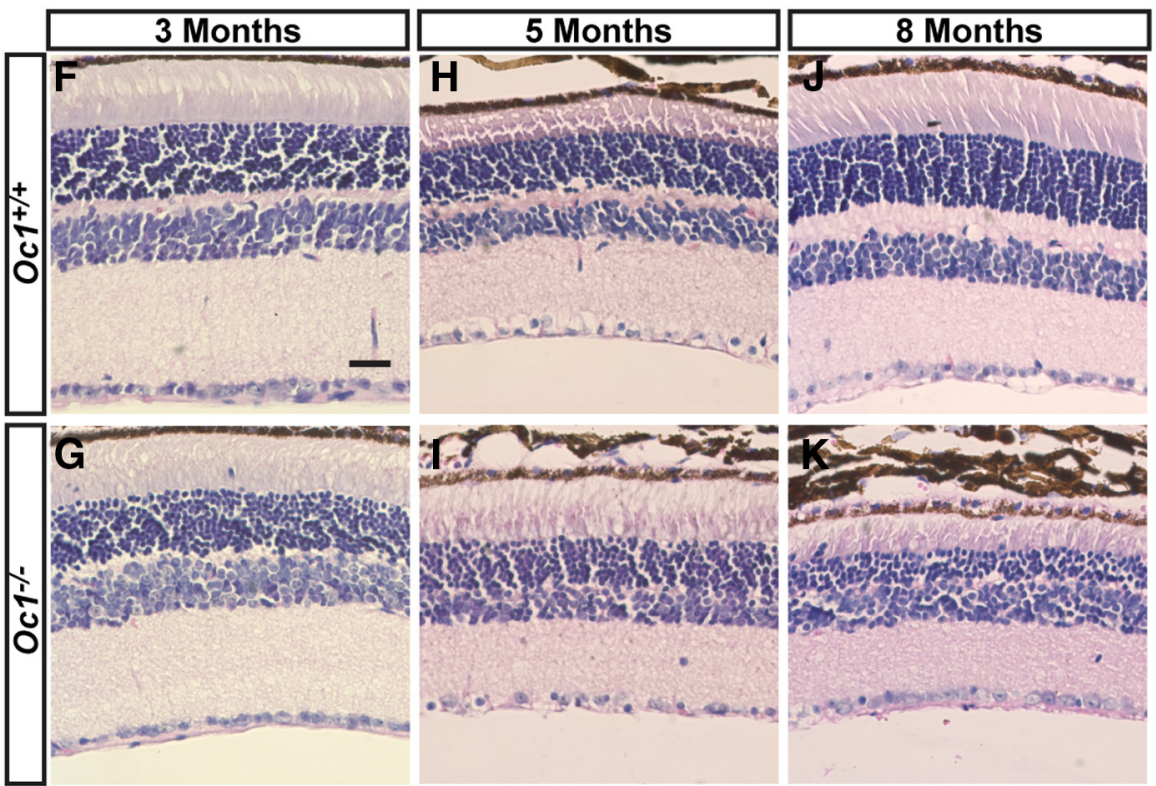

Figure 9. OC1-null mice exhibit abnormal ERGs and undergo retinal degeneration. $A-C$, Dark-adapted ERG. $A$, Average ERGs recorded from Oc1-null (MT) and littermate control (WT) retinas at 5 months of age in response to brief $(4 \mathrm{~ms})$ flashes. Flash intensities are indicated to the left of each trace. $B, C$, Intensity-response functions of b-and a-waves, respectively, recorded from $0 c 1$-null mice (MT, red) and their wild-type (WT) control siblings (black) at 5 months of age. Gray dashed lines indicate the response of WT mice divided by a factor of 3 . Error bars indicate SEM, $n=4$ in each group. $\boldsymbol{D}, \boldsymbol{E}$, Light-adapted ERGs. $\boldsymbol{D}$, Average ERGs recorded from Oc1-null (MT) and control retinas (WT) in response to brief $(4 \mathrm{~ms})$ flashes superimposed on a steady background of $10 \mathrm{~cd} / \mathrm{m}^{2}$. Intensities of the flashes are indicated in the left column. E, Intensity-response functions ofb-waves recorded from $0 C 1$-null mice (MT) and their wild-type (WT) siblings at 5 months of age. Gray dashed lines indicate the response of WT mice divided by a factor of 3 . Bars indicateSEM, $n=4$ in each group. $\boldsymbol{F}-\boldsymbol{K}$, Histological analysis of H\&Estained wild-type $(\boldsymbol{F}, \boldsymbol{H}, \boldsymbol{J})$ and $O \mathbf{C}(-$ null $(\boldsymbol{G}, \boldsymbol{I}, \boldsymbol{K})$ retinal sections from mice at 3 months $(\boldsymbol{F}, \boldsymbol{G}), 5$ months $(\boldsymbol{H}, \boldsymbol{I})$, and 8 months $(\boldsymbol{J}, \boldsymbol{K})$ of age shows progressive loss of photoreceptors in the 0 c 1 -null retina. See text for detailed description. Scale bar, (in $\boldsymbol{F}$ ) $\boldsymbol{F}-\boldsymbol{K}, 25 \mu \mathrm{m}$.

over much of the intensity range, indicating that the loss of HCs nonselectively impairs retinal function over the entire intensity range. The increase of the a-wave at $-2 \log s c \mathrm{~cd} \mathrm{~s} / \mathrm{m}^{2}$ probably resulted from the relative reduction of the b-wave and unmasking of the a-wave.
HCs provide lateral inhibitory input to photoreceptors as well as bipolar cells and are thought to contribute to light adaptation (Werblin and Dowling, 1969; Wu, 1992; Thoreson and Mangel, 2012). To determine whether light adaptation was impaired in Ocl-null retinas we recorded flash ERG responses in the presence of steady back- 
ground lights of $10 \mathrm{~cd} / \mathrm{m}^{2}$. These light levels produce $\sim 8000$ photoisomerizations/rod/s (Umino et al., 2012), which is sufficient to saturate rods (Nakatani et al., 1991) and induce light adaptation in cones (Dunn et al., 2007). We found that background illumination sped up the ERG response, reduced the amplitude of the b-wave, and limited the range of both wild-type and Oc1-null retinas to flash intensities $>-1 \log \mathrm{cd} \mathrm{s} / \mathrm{m}^{2}$ (Fig. 9D). However, much as in darkadapted conditions, the b-waves of $O c 1$-null retinas were $\sim 3$-fold smaller than those of control retinas over the entire intensity range (Fig. 9D,E). These results suggest that the cone-driven light responses in Oc1-null retinas are attenuated, although their light adaptive mechanisms appeared to remain intact.

Since we did not observe overt structural abnormalities in either the ONL or INL of Ocl-null retinas at P16, the impaired ERGs at 5 months of age prompted us to examine whether Ocl-null retinas underwent degeneration as the mice aged. At 3 months of age, the OPL was similarly defective as at P16. However, there were no obvious defects in the other layers of the Oc1-null retinas (Fig. $9 F, G$ ). In contrast, at 5 months, the OPL in Ocl-null retinas had virtually disappeared, while the thickness of the other retinal layers remained comparable to those in wild-type retinas. Some early signs of degeneration were noticeable in the ONL at this time: the ONL was slightly thinner and the nuclei in the ONL appeared less tightly packed than those in wild-type retinas (Fig. 9H,I). By 8 months of age, degeneration of photoreceptors was obvious in $\mathrm{Ocl} 1$-null retinas, with the thickness of the ONL being only approximately one-third that of wild-type retinas (Fig. 9J,K). The degeneration of the ONL in Oclnull retinas likely contributed to the reduction of the ERG a-waves under dark-adapted conditions. Nevertheless, the thickness of the INL did not change significantly, suggesting that the observed reduction in the ERG b-waves was due to diminished photoreceptor input, rather than bipolar cell loss. The observed age-dependent degeneration and loss of photoreceptors must be secondary to the loss of HCs in the Oc1-null retina, since photoreceptors do not express Ocl themselves and formed normally. Thus, in addition to processing visual signals, HCs are also essential for the postnatal survival of photoreceptors.

\section{Discussion}

\section{Roles of Oc1 in HC development and its potential redundancy} with Oc2

We previously showed that Ocl is expressed in developing HCs (Wu et al., 2012), but it was not clear from that study the stage at which Ocl is involved in HC development. Nevertheless, at E14.5, $\mathrm{Ocl}^{+}$cells, which are mostly postmitotic and typically do not coexpress factors that regulate the RGC lineage, exist in the NBL and their identities heretofore were not known (Wu et al., 2012). Our finding that deletion of $O c 1$ results in a loss of $\sim 80 \%$ of HCs and that this loss takes place early during HC development suggests that Ocl is required for the initial genesis of HCs. The lack of increased apoptosis in the Oc1-null retinas supports this idea. Further, we found that the $\mathrm{Oc}^{+}$cells located in the NBL are dependent on FoxN4. This observation, in combination with the deficient HC development in both FoxN4-null and Oc1null retinas, indicates that these $\mathrm{Oc}{ }^{+}$cells in the E14.5 NBL are $\mathrm{HC}$ precursors and arise from FoxN4 ${ }^{+}$progenitor cells. Upon expressing Ocl, they become committed to the $\mathrm{HC}$ fate and migrate inward to the boundary of the NBL and GCL, where they undergo further differentiation and begin expressing mature HC markers, including Lim1 and Prox1. Oc2 exhibits very similar expression patterns to those of $\mathrm{Ocl}$ in the developing retina (Wu et al., 2012). Since Oc1 and Oc2 are highly similar in their DNA-binding domains and bind to the same consensus sequence (Iyaguchi et al.,

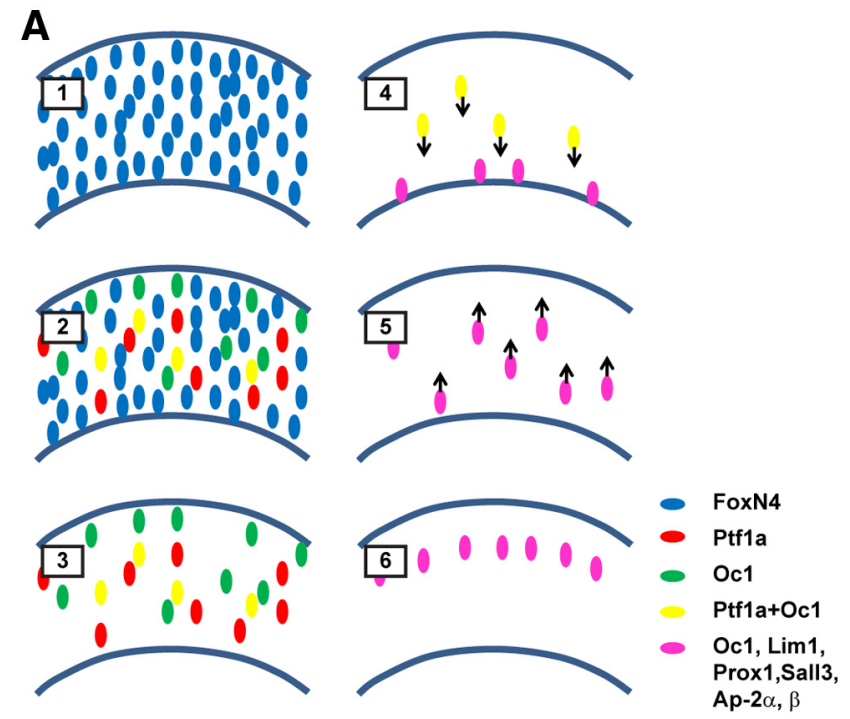

B

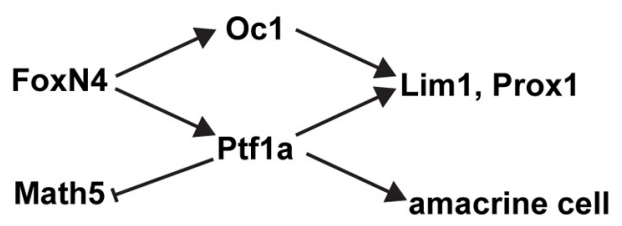

Figure 10. Summary diagram, illustrating key transcriptional regulators that regulate $\mathrm{HC}$ genesis. $\boldsymbol{A}$, Model for the genesis of HCs. 1, Expression of FoxN4 (blue) in a large subset, but not all, of retinal progenitor cells confers competence toward the HC fate. For simplicity, FoxN4 cells and the GCL are not depicted. 2, From HC-competent cells emerge two populations of cells: one expressing Ptf1a (red) and the other expressing $0 c 1$ (green). Only a small subset of cells coexpress both of these factors (yellow cells). 3, 0nly those cells that express both Ptf1a and 0c1 (yellow) adopt the HC fate. 4, Fate-determined HC precursors migrate basally and begin to express Lim1, Prox1, and Sall3 (pink). 5, These cells then migrate apically and begin to express other $\mathrm{HC}$ markers. 6, Nascent migrating $\mathrm{HC}$ s reach their final destination and differentiate into mature $\mathrm{HC}$. $\boldsymbol{B}$, Schematic illustration of the gene regulatory cascade underlying $\mathrm{HC}$ formation. FoxN4 is the most upstream factor, Ptf1a and $0 \mathrm{c} 1$ are downstream of FoxN4 and in parallel to each other, and Lim1 and Prox1 are downstream of 0c1 and Ptf1a. Ptf1a directs cells toward an amacrine cell fate in the absence of $0 \mathrm{c} 1$, and inhibits the ganglion cell fate by repressing Math5.

2007), it is possible that Oc1 and Oc2 function redundantly by regulating the same target genes in the developing retina. They both are expressed in all HCs during development and in adulthood. However, Oc2 is expressed in a much smaller cohort of HC precursors in the NBL during early development than is Oc1 (Wu et al., 2012). Consistent with this, only $\sim 20 \%$ of HCs still form in Oc1-null retinas and all of these remaining HCs express Oc2, suggesting that Oc2 is also involved in $\mathrm{HC}$ development.

Both Oc1 and Oc2 also are expressed in developing RGCs (Wu et al., 2012). However, we did not observe any RGC defects in the Oc1-null retina either during development or in adulthood. This also may be due to redundancy with Oc2, as suggested by the upregulation of Oc2 in Oc1-null retinas. Examining RGC development in the Oc2-null and Oc1/Oc2-double-null retinas in the future will help resolve this.

\section{The gene regulatory cascade for $\mathrm{HC}$ development}

The expression patterns and knock-out phenotypes of genes involved in HC development suggests a stepwise scenario of HC genesis (Fig. 10A). In this scenario, FoxN4 is most upstream and is expressed in a large population of, but not all, proliferating progenitor cells (Fig. 10A, 1). The function of FoxN4 is to render the progenitor cells competent for $\mathrm{HC}$ and amacrine cell fates. From these 
FoxN4-expressing cells emerge two distinct, but overlapping, cell populations: those expressing Ptfla and those expressing Ocl (Fig. $10 A, 2)$. Although both Ptfla and Ocl are essential for the HC fate, neither is sufficient individually. As indicated by in utero electroporation, most, if not all, cells expressing both factors will eventually adopt the HC fate (Fig. 10A, 2,3), i.e., Ocl and Ptfla act together to determine the $\mathrm{HC}$ fate. Those precursor cells expressing Ptfla alone become amacrine cells. In the Ocl-null retinas, precursor cells that normally adopt the HC fate may switch fate and become amacrine cells, since they now only express Ptfla; however, this remains to be demonstrated unequivocally by further experiments. At present, it is not clear what fate(s) cells expressing only Ocl adopt and what happens to them when $\mathrm{Ocl}$ is inactivated. The $\mathrm{HC}$ fate-committed cells then migrate to the basal side of the retina at $\sim$ E14.5 (Fig. 10A, 4) and begin to express transcription factors such as Lim1, Prox1, Sall3, and $\mathrm{AP}-2 \alpha$ and $\beta$, which regulate subsequent $\mathrm{HC}$ migration and differentiation (Dyer et al., 2003; Pochè et al., 2007; de Melo et al., 2011; Bassett et al., 2012). At later stages (e.g., E16.5), the immature HCs begin to migrate apically (Fig. 10A, 5), reach their final destination in the retina at $\sim \mathrm{P} 0$ (Fig. $10 A, 6$ ), and differentiate into mature $\mathrm{HCs}$, ultimately becoming part of visual circuitry. Clearly, HC formation is subject to regulation by a hierarchical pathway comprised of factors that include FoxN4, Ptfla, Oc1, Lim1, Prox1, SalI3, and AP- $2 \alpha$ and $\beta$ (Fig. 10B). Thus, our results identify Ocl as an essential player in this pathway, placing it downstream of FoxN4, in parallel with Ptfla, but upstream of Lim1, Prox1, Sall3, and AP- $2 \alpha$ and $\beta$ (Fig. 10B). It should be noted that Ptfla inhibits RGC formation by repressing Math5 (Fujitani et al., 2006; Lelièvre et al., 2011), and is also required for amacrine cell formation(Fujitani et al., 2006; Nakhai et al., 2007; Jusuf et al., 2011), indicating that this regulatory cascade also interacts with gene regulatory pathways for other retinal cell types (Fig. 10B). Currently it is not clear how Ocl and Ptfla collaborate to specify the $\mathrm{HC}$ fate. Interestingly, both Ptfla and Oc1 are expressed in the multipotent pancreatic progenitor cells and they coregulate the expression of Pdx1, a critical transcription factor for pancreas development (Jacquemin et al., 2006). Ptfla and Oc1 may coregulate downstream genes through a shared mechanism in the two tissues.

\section{HCs are essential for retinal integrity and function, and photoreceptor viability}

During normal development, HC processes are the first to contact photoreceptors; this leads to the recruitment of nascent synaptic ribbons to the site of contact, after which a second $\mathrm{HC}$ process is recruited and the synaptic complex begins to invaginate, followed by the subsequent addition of ON-type bipolar cell dendrites into the central position of the synaptic "triad" (Blanks et al., 1974). In Oc1-null retinas, this process is severely disrupted, although in some cases bipolar cell processes can still contact photoreceptor terminals and invaginations can still form. However, similar to the Bassoon knock-out retina (Dick et al., 2003), synaptic ribbons in the $O c 1$-null retina are rarely recruited to sites of contact with postsynaptic processes and formation of the stereotypical triadic synaptic complexes is impeded. The presence of these defects at p16, which coincides with the completion of photoreceptor synapse formation (Blanks et al., 1974) indicates that HCs are important for the establishment of normal synaptic connections in the OPL. The disruption of connectivity is entirely consistent with the abnormal ERG responses in the Oc1-null retina and indicates that the deficiency of HCs leads to severely compromised transmission of signals from photoreceptors to bipolar cells and the inner retina. Although it is clear that the synaptic organization of the OPL is disrupted in the Oc1-null retina, several important issues remain to be resolved including the extent of contacts, if any, that form between photoreceptors and $\mathrm{HCs}$, and whether HC deficiency disrupts the specificity of contact formation between photoreceptors and the various classes of bipolar cells. All these issues may be addressed by further analyzing the Oc1-null retinas, as well as the Oc1/Oc2-double-null retinas we have just created, which are expected to have more severe $\mathrm{HC}$ defects, at stages of synaptogenesis in the OPL during development. These future studies may reveal the exact roles HCs play during synaptogenesis in the OPL.

In addition, HCs are also essential for the integrity and maintenance of the photoreceptors in the adult retina. Because Oc1null retinas are largely normal when the mice are young, deficiency of $\mathrm{HC}$ formation does not affect the formation of the rest the retina on a large scale. However, severe retinal degeneration develops as the mice age. This is manifested mainly in the loss of photoreceptors, revealing a previously unrecognized but essential role for HCs in the survival of photoreceptors. Consequently, there were severe reductions in the a- and b-waves of the ERGs from these mice, although the change in the b-wave also likely arose from the severe compromise of synapse formation and the aberrant development of the presynaptic transmitter release machinery of the photoreceptor terminals due to reduction of HCs. Consistent with our findings, a recent study using a mouse model in which HCs were ablated by diphtheria toxin A revealed a similar degeneration of rod photoreceptors (Sonntag et al., 2012). The mechanism by which HCs promote and preserve photoreceptor viability is as yet unknown. It is possible HCs provide essential trophic factors for the survival of photoreceptors. Alternatively, electrical activity and/or feedback neurotransmission from HCs to photoreceptors may be required to maintain photoreceptor viability. Further investigations will be needed to identify the actual mechanisms involved. Once discovered, augmentation of these endogenous processes may provide a novel means of preventing photoreceptors from degenerating and dying in diseased retinas. Although retinal degeneration caused by HC deficiency has not been reported in humans, this model may have relevance to some types of hereditary retinal degenerations for which the underlying mechanisms are not yet understood and the genes involved have not been identified.

\section{References}

Agathocleous M, Harris WA (2009) From progenitors to differentiated cells in the vertebrate retina. Annu Rev Cell Dev Biol 25:45-69. CrossRef Medline

Bassett EA, Korol A, Deschamps PA, Buettner R, Wallace VA, Williams T, West-Mays JA (2012) Overlapping expression patterns and redundant roles for AP-2 transcription factors in the developing mammalian retina. Dev Dyn 241:814-829. CrossRef Medline

Blanks JC, Adinolfi AM, Lolley RN (1974) Synaptogenesis in the photoreceptor terminal of the mouse retina. J Comp Neurol 156:81-93. CrossRef Medline

Cepko CL, Austin CP, Yang X, Alexiades M, Ezzeddine D (1996) Cell fate determination in the vertebrate retina. Proc Natl Acad Sci U S A 93:589-595. CrossRef Medline

Cervetto L, MacNichol EF Jr (1972) Inactivation of horizontal cells in turtle retina by glutamate and aspartate. Science 178:767-768. CrossRef Medline

Cook JE, Chalupa LM (2000) Retinal mosaics: new insights into an old concept. Trends Neurosci 23:26-34. CrossRef Medline

de Melo J, Peng GH, Chen S, Blackshaw S (2011) The Spalt family transcription factor Sall3 regulates the development of cone photoreceptors and retinal horizontal interneurons. Development 138:2325-2336. CrossRef Medline

Dick O, tom Dieck S, Altrock WD, Ammermüller J, Weiler R, Garner CC, Gundelfinger ED, Brandstätter JH (2003) The presynaptic active zone 
protein bassoon is essential for photoreceptor ribbon synapse formation in the retina. Neuron 37:775-786. CrossRef Medline

Ding XQ, Nour M, Ritter LM, Goldberg AF, Fliesler SJ, Naash MI (2004) The R172W mutation in peripherin/rds causes a cone-rod dystrophy in transgenic mice. Hum Mol Genet 13:2075-2087. CrossRef Medline

Dunn FA, Lankheet MJ, Rieke F (2007) Light adaptation in cone vision involves switching between receptor and post-receptor sites. Nature 449: 603-606. CrossRef Medline

Dyer MA, Livesey FJ, Cepko CL, Oliver G (2003) Prox1 function controls progenitor cell proliferation and horizontal cell genesis in the mammalian retina. Nat Genet 34:53-58. CrossRef Medline

Espana A, Clotman F (2012a) Onecut transcription factors are required for the second phase of development of the A13 dopaminergic nucleus in the mouse. J Comp Neurol 520:1424-1441. CrossRef Medline

Espana A, Clotman F (2012b) Onecut factors control development of the Locus Coeruleus and of the mesencephalic trigeminal nucleus. Mol Cell Neurosci 50:93-102. CrossRef Medline

Francius C, Clotman F (2010) Dynamic expression of the Onecut transcription factors HNF-6, OC-2 and OC-3 during spinal motor neuron development. Neuroscience 165:116-129. CrossRef Medline

Fu X, Sun H, Klein WH, Mu X (2006) Beta-catenin is essential for lamination but not neurogenesis in mouse retinal development. Dev Biol 299:424-437. CrossRef Medline

Fu X, Kiyama T, Li R, Russell M, Klein WH, Mu X (2009) Epitope-tagging Math5 and Pou4f2: new tools to study retinal ganglion cell development in the mouse. Dev Dyn 238:2309-2317. CrossRef Medline

Fujitani Y, Fujitani S, Luo H, Qiu F, Burlison J, Long Q, Kawaguchi Y, Edlund H, MacDonald RJ, Furukawa T, Fujikado T, Magnuson MA, Xiang M, Wright CV (2006) Ptfla determines horizontal and amacrine cell fates during mouse retinal development. Development 133:4439-4450. CrossRef Medline

Furuno K, Ikeda K, Hamano S, Fukuyama K, Sonoda M, Hara T, Sasazuki T, Yamamoto K (2008) Onecut transcription factor OC2 is a direct target of T-bet in type-1 T-helper cells. Genes Immun 9:302-308. CrossRef Medline

Furuta Y, Lagutin O, Hogan BLM, Oliver GC (2000) Retina- and ventral forebrain-specific Cre recombinase activity in transgenic mice. Genesis 26:130-132. CrossRef Medline

Iyaguchi D, Yao M, Watanabe N, Nishihira J, Tanaka I (2007) DNA recognition mechanism of the ONECUT homeodomain of transcription factor HNF-6. Structure 15:75-83. CrossRef Medline

Jacquemin P, Lemaigre FP, Rousseau GG (2003) The Onecut transcription factor HNF-6 (OC-1) is required for timely specification of the pancreas and acts upstream of Pdx-1 in the specification cascade. Dev Biol 258:105-116. CrossRef Medline

Jacquemin P, Yoshitomi H, Kashima Y, Rousseau GG, Lemaigre FP, Zaret KS (2006) An endothelial-mesenchymal relay pathway regulates early phases of pancreas development. Dev Biol 290:189-199. CrossRef Medline

Jusuf PR, Almeida AD, Randlett O, Joubin K, Poggi L, Harris WA (2011) Origin and determination of inhibitory cell lineages in the vertebrate retina. J Neurosci 31:2549-2562. CrossRef Medline

Kay JN, De la Huerta I, Kim IJ, Zhang Y, Yamagata M, Chu MW, Meister M, Sanes JR (2011) Retinal ganglion cells with distinct directional preferences differ in molecular identity, structure, and central projections. J Neurosci 31:7753-7762. CrossRef Medline

Landry C, Clotman F, Hioki T, Oda H, Picard JJ, Lemaigre FP, Rousseau GG (1997) HNF-6 is expressed in endoderm derivatives and nervous system of the mouse embryo and participates to the cross-regulatory network of liver-enriched transcription factors. Dev Biol 192:247-257. CrossRef Medline

Lelièvre EC, Lek M, Boije H, Houille-Vernes L, Brajeul V, Slembrouck A, Roger JE, Sahel JA, Matter JM, Sennlaub F, Hallböök F, Goureau O, Guillonneau X (2011) Ptfla/Rbpj complex inhibits ganglion cell fate and drives the specification of all horizontal cell subtypes in the chick retina. Dev Biol 358:296-308. CrossRef Medline

Lemaigre FP, Durviaux SM, Truong O, Lannoy VJ, Hsuan JJ, Rousseau GG (1996) Hepatocyte nuclear factor 6, a transcription factor that contains a novel type of homeodomain and a single cut domain. Proc Natl Acad Sci U S A 93:9460-9464. CrossRef Medline

Li S, Mo Z, Yang X, Price SM, Shen MM, Xiang M (2004) Foxn4 controls the genesis of amacrine and horizontal cells by retinal progenitors. Neuron 43:795-807. CrossRef Medline

Margagliotti S, Clotman F, Pierreux CE, Beaudry JB, Jacquemin P, Rousseau GG, Lemaigre FP (2007) The Onecut transcription factors HNF-6/ OC-1 and OC-2 regulate early liver expansion by controlling hepatoblast migration. Dev Biol 311:579-589. CrossRef Medline

Masland RH (2001) The fundamental plan of the retina. Nat Neurosci 4:877-886. CrossRef Medline

Matsuda T, Cepko CL (2004) Electroporation and RNA interference in the rodent retina in vivo and in vitro. Proc Natl Acad Sci U S A 101:16-22. CrossRef Medline

Mu X, Fu X, Sun H, Liang S, Maeda H, Frishman LJ, Klein WH (2005) Ganglion cells are required for normal progenitor- cell proliferation but not cell-fate determination or patterning in the developing mouse retina. Curr Biol 15:525-530. CrossRef Medline

Mu X, Fu X, Beremand PD, Thomas TL, Klein WH (2008) Gene regulation logic in retinal ganglion cell development: Isl1 defines a critical branch distinct from but overlapping with Pou4f2. Proc Natl Acad Sci U S A 105:6942-6947. CrossRef Medline

Nakatani K, Tamura T, Yau KW (1991) Light adaptation in retinal rods of the rabbit and two other nonprimate mammals. J Gen Physiol 97:413435. CrossRef Medline

Nakhai H, Sel S, Favor J, Mendoza-Torres L, Paulsen F, Duncker GI, Schmid RM (2007) Ptfla is essential for the differentiation of GABAergic and glycinergic amacrine cells and horizontal cells in the mouse retina. Development 134:1151-1160. CrossRef Medline

Olney JW (1968) An electron microscopic study of synapse formation, receptor outer segment development, and other aspects of developing mouse retina. Invest Ophthalmol 7:250-268. Medline

Petros TJ, Rebsam A, Mason CA (2009) In utero and ex vivo electroporation for gene expression in mouse retinal ganglion cells. J Vis Exp pii:1333. CrossRef Medline

Poché RA, Kwan KM, Raven MA, Furuta Y, Reese BE, Behringer RR (2007) Lim1 is essential for the correct laminar positioning of retinal horizontal cells. J Neurosci 27:14099-14107. CrossRef Medline

Pochet R, Blachier F, Malaisse W, Parmentier M, Pasteels B, Pohl V, Résibois A, Rogers J, Roman A (1989) Calbindin-D28 in mammalian brain, retina, and endocrine pancreas: immunohistochemical comparison with calretinin. Adv Exp Med Biol 255:435-443. CrossRef Medline

Pugh EN Jr, Falsini B, Lyubarsky, AL (1998) The origin of the major rodand cone-driven components of the rodent electroretinogram and the effect of age and light-rearing history on the magnitude of these components. In: Photostasis and related phenomena (Williams TP, Thistle AB, ed.), pp 93-128. New York: Plenum.

Robson JG, Maeda H, Saszik SM, Frishman LJ (2004) In vivo studies of signaling in rod pathways of the mouse using the electroretinogram. Vision Res 44:3253-3268. CrossRef Medline

Roy A, Francius C, Rousso DL, Seuntjens E, Debruyn J, Luxenhofer G, Huber AB, Huylebroeck D, Novitch BG, Clotman F (2012) Onecut transcription factors act upstream of Isl1 to regulate spinal motoneuron diversification. Development 139:3109-3119. CrossRef Medline

Samadani U, Costa RH (1996) The transcriptional activator hepatocyte nuclear factor 6 regulates liver gene expression. Mol Cell Biol 16:6273-6284. Medline

Sonntag S, Dedek K, Dorgau B, Schultz K, Schmidt KF, Cimiotti K, Weiler R, Löwel S, Willecke K, Janssen-Bienhold U (2012) Ablation of retinal horizontal cells from adult mice leads to rod degeneration and remodeling in the outer retina. J Neurosci 32:10713-10724. CrossRef Medline

Stricker HM, Ding XQ, Quiambao A, Fliesler SJ, Naash MI (2005) The Cys214->Ser mutation in peripherin/rds causes a loss-of-function phenotype in transgenic mice. Biochem J 388:605-613. CrossRef Medline

Thoreson WB, Mangel SC (2012) Lateral interactions in the outer retina. Prog Retin Eye Res 31:407-441. CrossRef Medline

Umino Y, Herrmann R, Chen CK, Barlow RB, Arshavsky VY, Solessio E (2012) The relationship between slow photoresponse recovery rate and temporal resolution of vision. J Neurosci 32:14364-14373. CrossRef Medline

Wachtmeister L (1998) Oscillatory potentials in the retina: what do they reveal. Prog Retin Eye Res 17:485-521. CrossRef Medline

Wässle H, Boycott BB (1991) Functional architecture of the mammalian retina. Physiol Rev 71:447-480. Medline

Werblin FS, Dowling JE (1969) Organization of the retina of the mudp- 
uppy, Necturus maculosus. II. Intracellular recording. J Neurophysiol 32:339-355. Medline

Wu F, Sapkota D, Li R, Mu X (2012) Onecut 1 and Onecut 2 are potential regulators of mouse retinal development. J Comp Neurol 520:952-969. CrossRef Medline

Wu SM (1992) Feedback connections and operation of the outer plexiform layer of the retina. Curr Opin Neurobiol 2:462-468. CrossRef Medline

Xiang M (2013) Intrinsic control of mammalian retinogenesis. Cell Mol Life Sci 70:2519-2532. CrossRef Medline
Young RW (1985) Cell differentiation in the retina of the mouse. Anat Rec 212:199-205. CrossRef Medline

Zhang H, Ables ET, Pope CF, Washington MK, Hipkens S, Means AL, Path G, Seufert J, Costa RH, Leiter AB, Magnuson MA, Gannon M (2009) Multiple, temporal-specific roles for HNF6 in pancreatic endocrine and ductal differentiation. Mech Dev 126:958-973. CrossRef Medline 